\title{
TRIBUTOS NEGOCIADOS: LAS QUESTIE/SUBSIDIOS DE LAS VILLAS CATALANAS EN LA PRIMERA MITAD DEL SIGLO XIV
}

\author{
NEGOTIATED TRIBUTES: \\ THE “QUESTIE"/SUBSIDIES OF THE TOWNS OF CATALONIA \\ IN THE FIRST HALF OF THE FOURTEENTH CENTURY
}

\author{
MANUEL SÁNCHEZ MARTÍNEZ \\ Institución Milá y Fontanals, \\ CSIC. Barcelona
}

\begin{abstract}
Resumen: En este artículo se estudian las questie/subsidios pedidas por los monarcas catalanoaragoneses a las villas de realengo de Cataluña entre 1309 y 1359. Desde el punto de vista de la Corona, la importancia de estos tributos radica en que fueron la principal forma de financiación de la monarquía antes de las trascendentales transformaciones fiscales de las décadas de 1350 y 1360 . Y, desde la perspectiva de las villas, la necesidad de negociar con el rey y sus oficiales, año por año, el volumen de las questie/subsidios a pagar por cada pequeña ciudad contribuyó a la creciente autonomía financiera de los municipios y, más allá, a la vertebración social e institucional de la propia comunidad.
\end{abstract}

Palabras clave: Fiscalidad; Ciudades; Finanzas públicas.

\begin{abstract}
This article examines the questie/subsidies requested by the CatalanAragonese monarchs from the towns of the royal domain of Catalonia between 1309 and 1359. From the point of view of the Crown, the importance of these tributes lies in the fact that they were the monarchy's main way of financing prior to the transcendental changes in taxation of the decades of 1350 and 1360. And, from the point of view of the towns, the necessity to negotiate with the king and his officials, year after year, the amount of the questie/subsidies due in every small city, contributed to the increasing financial autonomy of the municipalities and, beyond that, to the social and institutional coordination of that community.
\end{abstract}

Keywords: Taxation; Cities; Public finances.

\section{SUMARIO}

I. Introducción.- II. La questia/subsidio: un tributo negociado.- III. Las questie/subsidios entre 1309 y 1359: 1. La "edad de oro" de las questie/subsidios (1309-1333. 2. Questie/subsidios, Cortes y Parlamentos (1334-1340). 3. La disolución de la questia/subsidio (1340-c.1348). 4. El destino de las questie entre 1348 y 1359.- IV. Consideraciones finales.- Apéndice. 


\section{INTRODUCCIÓN}

Esta comunicación se inscribe en el marco de uno de los objetivos perseguidos por este Coloquio, que se expresa muy bien en la circular que acompañaba a su convocatoria: " "es evidente que, en el proceso de asunción progresiva de personalidad social, jurídica y política por parte de la comunidad, el hecho fiscal jugó un papel muy importante, cuando no decisivo; en este sentido, la evolución de las prerrogativas fiscales y financieras de las comunidades urbanas se presenta como uno de los elementos más ejemplificadores y mejor documentados de este proceso". Teniendo muy presente estas palabras, voy a revisitar un viejo tema, observando fundamentalmente lo que la documentación referida al pago del tributo regio de la questia puede aportar al mejor conocimiento de algunas villas catalanas en la primera mitad del s. $\mathrm{XIV}^{2}$.

Antes de entrar de lleno en el tema, me gustaría mostrar la importancia de las questie/subsidios desde un doble punto de vista. En primer lugar, desde la perspectiva de la fiscalidad real, las questie/subsidios, que más adelante intentaré explicar, señalan el camino por donde transitó la principal fuente de financiación de la Corona en Cataluña hasta mediados del s. XIV. En efecto, dejando atrás los bovatges del Doscientos y los subsidios generales obtenidos en Cortes a finales de esa centuria (1289 y 1292), la monarquía financió gran parte de los conflictos bélicos y de los gastos inherentes al crecimiento del Estado con los subsidios pedidos a las comunidades cristianas y judías, siempre dentro de los límites del dominio o patrimonio regio ${ }^{3}$. Por tanto, hasta las grandes innovaciones ocurridas en las décadas de 1350 y 1360 , las questie/subsidios pedidas a las villas fueron la expresión más clara y mejor documentada de la fiscalidad real en el Principado.

${ }^{1}$ Este trabajo fue originariamente presentado en el Coloquio sobre Les viles catalanes entre els segles XII iXIV: senyoria, comunitat i estructures fiscals, que se celebró en Gerona los días 15,16 y 17 de noviembre de 2001.

${ }^{2}$ Hace ya más de un cuarto de siglo me ocupé de estas cuestiones en M. SÁNCHEZ, "Questie" y subsidios en Cataluña en el primer tercio del siglo XIV: el subsidio para la cruzada granadina (1329-1334) "Cuadernos de Historia Económica de Cataluña", XV (1976), p. 11-54. Si bien creo que este trabajo sigue conservando su validez por lo que respecta a los subsidios concretos pedidos para la cruzada granadina de 1329-1334 ciertos razonamientos - y algunos despistescontenidos allí eran tributarios de lo poco que sabíamos hacia 1975 sobre la fiscalidad real y las finanzas locales.

${ }^{3}$ Sobre el bovatge, véase P. ORTí Gost, La primera articulación del Estado feudal en Cataluña a través de un impuesto: el bovaje (ss. XII-XIII), "Hispania", LXI/3, núm. 209 (2001), p. 967998; y sobre los subsidios en Cortes a finales del S. XIII M. SÁNCHEZ; P. ORTI, Corts, Parlaments i fiscalitat a Catalunya. Els capítols del donatiu (1288-1384), Barcelona, 1997, docs. I, II, III y IV, p. 1-32. Acerca de los subsidios exigidos a las aljamas de judíos, véase M. SÁNCHEZ La fiscalidad catalanoaragonesa y las aljamas de judíos en la época de Alfonso IV (1327-1336), "Acta Historica et Archaeologica Mediaevalia", III (1982), p. 93-141. 
Desde la perspectiva de las villas, también las questie/subsidios tuvieron una destacada relevancia. Ante todo, tal y como hemos postulado en otros lugares, creemos que el principal motivo que impulsó a las comunidades a repartir tallas proporcionales (esto es, per solidum atque libram) fue la necesidad de pagar, con periodicidad casi anual, la questia real. Quiere ello decir que esta primera manifestación de la fiscalidad municipal -0 , si se quiere, el primer pilar de las finanzas locales, para utilizar la expresión de Font Rius - tuvo como uno de sus principales motores la ineludible obligación de pagar aquel tributo a la Corona por encima de otros gastos ocasionales de la comunidad, probablemente poco importantes en los primeros años del s. $\mathrm{XIV}^{4}$. Pero, con ser ésta muy importante, la incidencia del pago de la questia sobre las comunidades catalanas trascendió con mucho el ámbito estrictamente fiscal. En efecto, la necesidad de enviar representantes de las universidades ante el monarca para negociar el subsidio o una eventual rebaja de la questia; y, sobre todo, los problemas planteados por el reparto diferenciado de las tallas para pagarla dieron un impulso decisivo a la propia organización social e institucional de la comunidad ${ }^{5}$.

El objetivo concreto de esta comunicación será observar a grandes rasgos las questie/subsidios exigidas por Jaime II, Alfonso el Benigno y Pedro el Ceremonioso a las villas catalanas entre los umbrales del s. XIV y los años centrales de la centuria. Creo que el material analizado puede ser de cierta importancia para el historiador de las villas catalanas, que tendrá casi todos los elementos, así como las adecuadas referencias archivísticas, para conocer a qué lugares, con qué frecuencia, porqué motivo y con qué volumen la Corona solicitó subsidios. Pero, más allá de la frialdad de estos datos y a través de una documentación de carácter más incidental, también será posible conocer algunas particularidades locales que tienen que ver con la propia historia de cada villa. Con todo, lo más relevante para el investigador de estos núcleos urbanos es que tendrá la posibilidad de descubrir la naturaleza del

\footnotetext{
${ }^{4}$ Véanse J.M ${ }^{\text {a }}$ FONT RIUS, La administración financiera en los municipios catalanes medievales, en J.M ${ }^{\mathrm{a}}$ FONT RIUS, Estudis sobre els drets $i$ institucions locals en la Catalunya medieval, Barcelona, 1985, p. 611-637; M. SÁNCHEZ; P. ORTÍ, La Corona en la génesis del sistema fiscal municipal en Cataluña (1300-1360), en Col.loqui sobre "Corona, municipis i fiscalitat a la baixa Edat Mitjana", Lleida, 1997, p. 233-278.

${ }^{5}$ Uno de los autores que más ha insistido en esta cuestión es Max Turull: ha mostrado, por ejemplo, que la existencia de un arca común en Lleida (1196) antecede en un año a la instauración del consulado; $y$, por lo que respecta a las dos grandes villas de Cervera y Tàrrega, el mismo autor subraya que el consejo surgido en algunos años del primer tercio del s. XIV (en 1294 y 1313 en Tarrega; y en 1311 y 1331 en Cervera) tenía como objetivo prioritario facilitar la administración tributaria de ambas villas; véanse M. TURULL, El naixement de la fiscalitat municipal a Lleida (1149-1289), en Col-loqui sobre "Corona, municipis i fiscalitat", cit., p. 219232; Nuevas hipótesis sobre los orígenes de los consejos municipales en Cataluña (siglos XIIXIII): algunas reflexiones, "Anuario de Historia del Derecho Español”, LXXII (2002), p. 461471; y, sobre todo, "Universitas, commune, consilium". sur le rôle de la fiscalité dans la naissance et le développement du Conseil (Catalogne, XXe-XंIVe siècles), en "Excerptiones iuris". Studies in Honor of André Gouron, ed. by B. Durand and L. Mayali, The Robbins Collection, 2000, p. 637-677.
} 
diálogo mantenido entre la Corona y las villas catalanas en torno a la fiscalidad y, a partir de ahí, intuir el creciente proceso de afirmación política, institucional y fiscal de cada comunidad.

El interés de los datos que voy a proporcionar - procedentes siempre de documentación cancilleresca- reside básicamente en su fecha. Es de sobra sabido que, salvo excepciones como Manresa o Cervera (entre otras), no existe documentación municipal relativamente nutrida y continua hasta, por lo menos, la segunda mitad del s. XIV. Por tanto, en la mayoría de los casos, la información relativa a las villas con anterioridad a 1350/1360 debe obtenerse en lo esencial de la documentación "central", es decir, de la emanada de la cancillería real. E incluso en los contados casos en que la villa en cuestión conserve documentación más o menos abundante para la primera mitad del s. XIV, el material procedente de la cancillería real siempre la complementa con eficacia ${ }^{6}$.

Tal y como los organizadores del Coloquio aconsejábamos a los participantes, voy a detenerme muy brevemente en el tipo de documentación utilizado. Como acabo de decir, el material procede en su integridad de la serie de registros de cancillería del Archivo de la Corona de Aragón (ACA), llamada primero Subsidiorum y después - concretamente, desde los años centrales del siglo-Demandarum. Se contienen en estos registros todos y cada uno de los subsidios pedidos por la Corona al realengo: questie catalanas, pechas aragonesas y peitas valencianas; subsidios a las comunidades musulmanas y judías, peticiones esporádicas a establecimientos eclesiásticos, a los lugares que fueron de la orden templaria después de su disolución, etc. Por tanto, un análisis sistemático de estas series de registros desde finales del s. XIII nos proporcionaría un cuadro muy completo de la fiscalidad real a lo largo de los últimos siglos medievales.

Centrándome ya en Cataluña, debo hacer una advertencia que tiene que ver con la especial configuración del territorio que voy a observar. Ya sea por sus particularidades específicas o por su especial proceso de incorporación a la Corona, las peticiones de subsidios al Principado aparecen agrupadas bajo rúbricas diferentes: por ejemplo, el valle de Arán, las peitas de Pallars y Ribagorza, las questie de la baronía de Montcada y las del Rossellón-Cerdaña, a partir de su reintegración a la Corona en la década de 1340. Separadas de ellas, aparecen las peticiones dirigidas a las universitates Cathalonie, que engloba a las villas reales del Principado y que aquí retendrá mi atención.

\footnotetext{
${ }^{6} \mathrm{He}$ insistido en esta cuestión numerosas veces, por ejemplo, en M. SÁNCHEZ, Fiscalité royale et fiscalité municipale en, Catalogne (XIVe siêcle), en D. MENJOT; M. SÁNCHEZ, La fiscalité des villes au Moyen Age. 1. Etude des sources, Toulouse, 1996, p. 135-146. Véase también, para un caso concreto, M. SÁNCHEZ, Fiscalidad real y villas en Cataluña: de la ordenación del subsidio a su liquidación (El ejemplo de la questia/subsidio de 1338 y la villa de Cervera, en D. MENJOT; M. SÁnCHEZ, La fiscalité des villes au Moyen Age. IV. La gestion de l'impôt, Toulouse, 2004, p. $91-107$.
} 
Quiero decir con todo ello que no voy a analizar las questie pedidas a todo el territorio catalán, sino precisamente las exigidas a aquellas universitates Cathalonie, donde se incluyen los núcleos urbanos más importantes y significativos.

¿Cómo aparece la información en estos registros?. Bajo una rúbrica donde figuran los destinatarios y la causa de la petición (por ejemplo, subsidium postulatum ab universitatibus Cathalonie racione coronacionis....matrimonii...guerre Granate, etc.), viene, en primer lugar, la carta circular donde se especifica con mayor detalle el motivo del subsidio y se indican la cantidad exigida a cada villa, los plazos de pago y el nombre del recaudador. Tras el habitual similis, sigue la relación de todas las villas con la cantidad solicitada, escrita al margen, y, bajo cada uno de estos datos, se anota brevemente la posterior remisión obtenida por la villa, con especificación de la cantidad perdonada y la fecha de dicha remisión. Al final, cerrando esta sección del registro, aparecen un conjunto de cartas (casi siempre bajo el epígrafe sparse) dirigidas a los recaudadores, a los oficiales reales o a los propios regidores urbanos, donde se precisan determinadas cuestiones relativas a la recaudación. Son algunas de estas cartas las que suelen suministrar informaciones de relieve sobre la historia interna de la villa en cuestión y las relaciones de los regidores con la Corona en materia fiscal.

Por tanto, la documentación contenida en esta serie de registros nos muestra perfectamente lo que podríamos llamar el primer acto de la secuencia fiscal protagonizada por la Corona y las villas. A través de aquella, podemos saber con qué fecha, porqué causa, a qué villas y con qué cantidad el monarca solicitaba una questia/subsidio a los núcleos de realengo; podemos conocer también los plazos de pago, las eventuales remisiones obtenidas por los dirigentes urbanos y la identidad de los recaudadores. Por fortuna, en la mayoría de los casos también es posible disponer de otro tipo de documentación que nos informa sobre el último acto del ciclo fiscal: me refiero a los albaranes testimoniales extendidos por el Maestro Racional de la corte a los distintos recaudadores, una vez auditadas sus cuentas. Ello nos permite conocer las cantidades efectivamente recaudadas y, lo que es aún más importante, saber el destino posterior de las mismas, muchas veces muy alejado de la causa por la que se solicitaron. En una palabra, gracias a esta documentación, podemos calibrar el resultado del esfuerzo fiscal desplegado por la Corona y la plasmación práctica de las negociaciones llevadas a cabo en la corte por los mensajeros de las villas. Como en esta ocasión mi interés se centra no tanto en las finanzas regias como en la propia historia de las pequeñas ciudades, no he utilizado aquí los mencionados albaranes ${ }^{7}$. Si,

${ }^{7}$ Cosa que he hecho en otras ocasiones, por ejemplo, en M. SÁNCHEZ, "Questie” y subsidios, cit.; Las aljamas catalanoaragonesas, cit. o en La fiscalidad extraordinaria en el reino de Aragón durante el primer tercio del siglo XIV: los subsidios para la campaña granadina (1329-1333), "Revista de Historia J. Zurita", 67-68 (1993), p. 7-41. 
además, tenemos la suerte de localizar libros del consell o de clavaria de algunas villas, estaremos en condiciones de conocer también el segundo e importante acto de todo el ciclo fiscal, es decir, saber qué medidas adoptaron los dirigentes municipales ante las exigencias de la Corona y a qué instrumentos -fiscales o no fiscales- recurrieron para pagar el subsidio ${ }^{8}$.

Como he dicho más arriba, vamos a observar las questie/subsidios pedidas a las villas catalanas durante la primera mitad del s. XIV, más concretamente, entre 1309 y 1359. La elección de la primera fecha se debe a razones documentales: aunque la serie de registros que voy a utilizar contiene algunos subsidios pedidos por Jaime II en la década de 1290, estos datos son relativamente escasos y, además, existe una gran laguna de diez años entre 1299 y 1309. En cambio, a partir de esta última fecha, los registros son continuos y permiten seguir perfectamente la evolución de estos tributos durante toda la primera mitad del siglo .

La elección de 1359 como témino de mi investigación es un tanto más arbitraria, ya que corresponde al momento en que las escasas questie que el rey percibía todavía en Cataluña fueron asignadas a la casa del infante Juan, duque de Girona y futuro rey Juan I; y, por tanto, estos tributos dejan de visualizarse en las series de registros utilizadas. Se me dirá que no es una razón de peso puesto que, a pesar de su alienación del patrimonio real, las questie seguirían pesando sobre las villas catalanas. Pero es que, al filo de 1359 , en un escenario donde la fiscalidad real había cambiado radicalmente, las questie eran ya algo muy diferente a lo que habían representado veinte o treinta años antes, como intentaré mostrar en las páginas siguientes.

\section{LA QUESTIA/SUBSIDIO: UN TRIBUTO NEGOCIADO}

Insistamos un poco en las características de las tantas veces mencionadas questie/subsidios.

Como es sabido, la questia era un tributo de carácter señorial que el monarca, como cualquier otro señor en sus tierras, tenía el derecho a exigir a los habitantes del realengo y que éstos tenían la obligación de pagar ex

\footnotetext{
${ }^{8}$ Véase como ejemplo M. SÁNCHEZ, Fiscalidad real y villas en Cataluña: de la ordenación del subsidio a su liquidación, cit.

${ }^{9}$ Naturalmente, sería posible - y deseable - remontarse hasta mediados del s. XIII para analizar la percepción de las questie en Cataluña (como las pechas aragonesas y las peitas valencianas) a partir de aquel momento. Pero el estudio de estas peticiones entraría de lleno en los todavía poco conocidos orígenes de estos tributos, cuestión que queda fuera de mi objetivo presente; vease, por ejemplo, el sugerente trabajo de J. TORRÓ, Colonització $i$ renda feudal. L'origen "de la "peita" al regne de de València, en Col loqui sobre "Corona, municipis i fiscalitat", p. 467-494.
} 
debito $^{10}$. Hemos de postular que, al principio, la questia debía ser arbitraria por lo que respecta a la periodicidad y volumen de su exacción, pero también tenemos motivos para pensar que, desde mediados o a partir del último tercio del s. XIII, las cantidades que pagaban como questie las ciudades y villas de realengo habían quedado progresivamente fijadas, bien de forma consuetudinaria o por expreso privilegio real ${ }^{11}$. Por otra parte, desde mediados del Doscientos, junto a la percepción prácticamente anual de la questia y la fijación de este tributo en una determinada cantidad a pagar por cada comunidad, vemos aparecer la dualidad questia/subsidio: el monarca, aprovechando la ocasión de la questia (o, si se quiere, embebiéndola en la obligación de pagar ésta), solicitaba una cantidad superior, invocando siempre una causa concreta como podía ser la coronación y el matrimonio del monarca, el casamiento de sus hijas, la guerra contra los musulmanes o cualquier otra necessitas inminente ${ }^{12}$. Por tanto, nos encontramos ante una doble petición vehiculada por una sola: por citar un ejemplo, cuando, en los primeros años de la década de 1330, Alfonso el Benigno pedía a Vilafranca

\footnotetext{
${ }^{10}$ Véanse algunos datos sobre este tributo y su incidencia concreta en la ciudad de Barcelona en P. ORTÍ, Renda i fiscalitat en una ciutat medieval: Barcelona, segles XII-XIV. Barcelona, 2000 p. 584-591. Como se dice en un documento de 1330 referido a ocho mansos del término castral de Mura, el monarca Alfonso el Benigno tenía el derecho a exigir questia en tanto que sus habitantes eran homines nostri proprii et de dominicatura nostra (ACA, reg. 543, fol. 167v.). Véanse también unas interesantes consideraciones sobre las questie solicitadas por los nobles en los distritos castrales y por los señores eclesiásticos en sus dominicaturas durante los siglos XII y XIII en P. BENITO I MONCLÚS, Senvoria de la terra $i$ tinenca pagesa al comtat de Barcelona (segles XI-XंIII), Barcelona, 2003, p. 421-426. Este autor afirma que la frecuencia de las questie señoriales aumentó sensiblemente en el período crítico de 1193-1205, esto es, durante el reinado de Pedro el Católico. Es significativo que también nosotros hemos avanzado la hipótesis de que las questie reales se generalizaron a todo el Principado en los años de aquel mismo monarca (cf. M. SÁNCHEZ, El naixement de la fiscalitat d'Estat a Catalunya (segles XII-XIV), Eumo Edit. I Universitat de Girona, 1995, p. 39-40). Por tanto, de la misma manera que la frecuencia de las questie en el ámbito señorial sería una forma de hacer frente a la caída de los ingresos ordinarios (P. Benito), la generalización de aquellos tributos por parte de Pedro el Católico respondería también a los intentos de compensar la continua degradación del patrimonio real en una coyuntura de apremiantes necesidades financieras.

${ }^{11}$ Por ejemplo, entre 1255 y 1299 . Barcelona pagaba al monarca unas questie que invariablemente ascendian a $100.000 \mathrm{s.,} 80.000 \mathrm{~s}$. y $60.000 \mathrm{~s}$. (cf. P. ORTí, Renda i fiscalitat, cit., p. 588590). Por lo que respecta al carácter arbitrario de la questia, todavía a mediados del s. XV , el monarca exigia a las villas de Piera y Sarral (acabadas de reincorporar al patrimonio real) una quèstia de mercè e arbitrària; y, por la misma época, los habitantes del çastillo de La Geltrú abonaban questia o do voluntari, la qual acustuma tatxar lo senyor del dit castell o son batle cascun any a son voler e arbitre (cf. M. SÁNCHEZ, Una aproximación a la estructura del dominio real en Cataluña a mediados del siglo XV, en M. SÁNCHEZ (comp.), Estudios sobre renta. fiscalidad y finanzas en la Cataluña bajomedieval, Barcelona, 1993, p. 419-420 y nota 134).

${ }^{12}$ Existe una precoz noticia de 1203 , según la cual los habitantes de Sant Celoni no pagarían questia a su señor (la Orden del Hospital) salvo "si tanta rationabile causa et evidens necessitas domui Hospitali emeserit", en cuyo caso, se podría "postulare... ab eis subsidium moderatum" (cit. por P. ORTÍ, Renda $i$ fiscalitat, cit., p. 586, nota 1430). Todavía podríamos citar otro ejemplo un poco más tardío: las pequeñas villas catalanas de Sedó y Riber tenían fijada su questia en 200 s. por privilegio de Jaime 1, "retento nobis quod, si pro evidenti necessitate nostra vel terre nostre, exigeremus generaliter questie vel subsidia..." (reg. 327, fols. 198r.-204v.). En última instancia, el propio título que encabeza las diferentes cartas circulares de petición distingue netamente las ocasiones en que se pedía el subsidio por una causa concreta "Subsidium postulatum...racione matrimonii" o "racione guerre Granate" o "racione coronacionis", etc.) de aquellas otras en que se exigía simplemente una cantidad "pro questia anni presentis", como veremos que sucedería desde el final de la década de 1340.
} 
del Penedès un subsidio de 20.000 s., de 30.000 s. o de 40.000 s. para la guerra de Granada, estaba claro que la questia ordinaria que aquella villa estaba obligada a pagar era sólo de $10.000 \mathrm{~s}$. y que la cantidad suplementaria estaba constituida por el subsidio a negociar.

Como he apuntado, la práctica de las questie/subsidio está atestiguada desde mediados del s. XIII, por lo menos en el caso bien conocido de la ciudad de Barcelona. Sugiere P. Ortí que la dualidad questia/subsidio quizás respondiese al intento de frenar la creciente merma para la Corona de este tributo, debido a la progresiva fijación de las cantidades a pagar y a las numerosas franquicias de que empezaron a gozar muchas ciudades y villas. Por ello, a través de un subsidio debidamente justificado, los monarcas pretendieron hacer contribuir también a los lugares francos y obtener de los otros una cantidad superior a la questia consuetudinaria ${ }^{13}$.

En cierto modo, todo ello está mostrando los límites del poder real en materia tributaria: es evidente que el monarca podía exigir la questia ordinaria, que le correspondía ex debito; pero, si deseaba obtener una cantidad suplementaria (sobre todo, si la questia había sido fijada por privilegio real) o recibir alguna ayuda de los lugares exentos de este tributo, el único camino era la negociación con los representantes de las villas. Unos casos relativamente precoces y bien documentados de estos subsidios negociados fueron los de Barcelona y Perpiñán, ciudades que, en 1254, recibieron sendas cartas de indemnidad, donde se reconocía el carácter gracioso de un subsidio pedido por urgentes necesidades de la Corona ${ }^{14}$. Habría que estudiar ejemplos semejantes, para el s. XIII, de una práctica que será general y rutinaria durante la primera mitad de la siguiente centuria. En esta época, que es la que aquí vamos a considerar, el proceso es bastante claro: cada vez - prácticamente, cada añoque el monarca solicitaba un subsidio asociado a la questia, la ciudad, villa o lugar destacaban sus representantes a la corte para negociar el alcance del tributo, procurando que éste no se alejase demasiado de la cantidad que habitualmente pagaban como questia ordinaria ${ }^{15}$. Creo que éste es un dato importante para comprobar el nivel de madurez institucional de las villas catalanas: como puede fácilmente intuirse, el envío anual de procuradores a la corte con capacidad para representar la voluntad de la universidad y negociar el alcance del subsidio a pagar presupone una mínima organización

\footnotetext{
${ }^{13}$ P. ORTí, Renda i fiscalitat, cit., p. 585-586.

${ }^{14} \mathrm{P}$. ORTÍ, Renda i fiscalitat, cit., p. 587-588.

${ }^{15}$ Hace más de 25 años, cuando estudiaba las questie/subsidios pedidas entre 1329 y 1334 quedé sorprendido ante el hecho de que el monarca solicitase unos cuantiosos subsidios a los lugares de realengo mientras el total efectivamente recaudado - poco más que la questia ordinaria- era prăcticamente el mismo año tras año (cf. M. SÁNCCHEZ, "Questie" y subsidios, cit., gráfico de la p. 46). Y me sorprendía también la aparente rutina del procedimiento: el rey pedía una cantidad concreta a cada villa y, poco tiempo después, procedía sistemáticamente a conceder una remisión que, en la mayoría de los casos, ascendía al $60 \%$ u $80 \%$ de la cantidad solicitada. Ignoraba entonces el proceso negociador que se ponía en marcha cada vez que se pedía una questia/subsidio.
} 
comunitaria. Y presupone también la existencia de unos recursos fiscales y de unos instrumentos financieros, por rudimentarios que fuesen, no sólo para abonar al rey la cantidad finalmente pactada sino para hacer frente asimismo a los respetables gastos generados por la mensajería: dietas, derechos de cancillería, eventuales sobornos, etc. Es importante subrayar que estos procesos se observan no sólo en ciudades como Manresa o en una gran villa como Cervera sino en núcleos tan minúsculos como Gurb de la Plana, Gàver o Tagamanent, que también destacaban sus procuradores para negociar el subsidio $^{16}$.

El carácter de la escasa documentación conservada no nos permite conocer los términos exactos de la negociación y, salvo en algunas contadas ocasiones, las causas de las remisiones otorgadas por el monarca. Detengámonos un instante en los lugares dotados de franquicia, donde se había roto el vínculo del subsidio con la questia y donde, en consecuencia, el rey no podía exigir ninguna cantidad por su autoridad. En estos casos, los enviados de las villas debieron jugar fuerte en la corte para arrancar algunas concesiones a cambio de conceder un subsidio al que no estaban obligados. Veamos un ejemplo particularmente claro al respecto. En 1330, Alfonso el Benigno solicitó una questia/subsidio con motivo de la campaña que preparaba contra el sultanato de Granada ${ }^{17}$. Mientras a las villas no dotadas de franquicia el rey pedía la ayuda en la forma habitual, esto es, exigiendo (dicimus et mandamus) determinadas cantidades, a las villas francas fue enviado el propio batlle general de Cataluña, Ferrer de Lillet, para lograr - rogando- un subsidio apropiado $^{18}$. Aunque no conozcamos por el momento el contenido preciso de la negociación, el resultado de la misma es bastante sugerente. En algunos casos, el monarca aceptaba la cantidad que las villas ofrecieron graciosamente: así sucedió con los 2.000 s. de Figueres, los 500 s. de Palamós o los 4.000 s. de Besalú ${ }^{19}$. En el caso de L'Arbóç, el monarca sólo aceptó 2.000 s. de los $3.000 \mathrm{~s}$. que la villa ofrecía graciosamente y ello a cambio de que le fuesen

\footnotetext{
${ }^{16}$ Por ejemplo, en 1373, los prohoms de Montmaneu/La Panadella obtuvieron del infante Juan la fijación de su questia para evitar que "vos fatigemini laboribus et expensis in obtinendo a curia domini regis vel nostra remissionem annis singulis..." (reg. 1680, fol. 48r.)

${ }^{17}$ Véase M. SÁNCHEZ, “Questie” y subsidios, cit., p. 22-24.

${ }^{18}$ Este doble carácter queda patente en el propio título de las cartas de petición: en el primer caso: "Subsidium postulatum ab universitatibus Cathalonie pro negocio guerre Granate..."; $\mathrm{y}_{\text {, }}$ en el caso de las villas exentas: "Alia forma subșidii rogando postulari ab aliis universitatibus Cathalonie propter franquitates et alias concessiones quos habent..." (reg. 543, fols. 121r. y 126r.).

${ }^{19}$ Figueres estaba exenta de questia por privilegios de Jaime I y de Jaime II, de 1267 y 1295 respectivamente; lo mismo cabe decir de Palamós, libre de questia según la carta de franquicias de 1279 (véase M. SÁNCHEZ, "Questie” y subsidios, cit., p. 16, notas 15 y 16). Por fin, desde 1305. Besalú estaba exenta durante diez años del pago del tributo, siempre que se empleasen $2.000 \mathrm{~s}$. anuales en las obras del puente de la villa, franquicia prolongada dos años y 20 años más en 1314 y 1320 respectivamente (reg. 326, fol. 75r., reg. 327, fols. 155r.-v. y reg. 329, fol. $273 v$.).
} 
confirmados los privilegios otorgados por Jaime $\mathrm{II}^{20}$. Por fin, el monarca rechazó lisa y llanamente los 10.000 s. ofrecidos por la ciudad de Manresa y los $1.000 \mathrm{~s}$. que prometía dar Torroella de Montgrí ${ }^{21}$. Estos ejemplos, que distan mucho de ser únicos, aparte de mostrar con meridiana claridad la diferencia entre la questia obligatoria y el subsidio pactado, permiten intuir, como he dicho más arriba, los términos generales de la negociación. Parece evidente que los mensajeros de aquellas villas francas de questia o que tenían fijado este tributo en una cantidad determinada solicitarían de la Corona algún tipo de concesión a cambio de otorgar un subsidio voluntario (sponte). En algunos casos, el monarca debió conceder todo o parte de lo solicitado y aceptó, en consecuencia, todo o parte del subsidio ofrecido libremente (caso de L'Arbóç). En otras ocasiones, las peticiones de las villas debieron ser superiores a lo que el monarca estaba dispuesto a otorgar y, en este verdadero mercadeo entre las dos partes, el soberano acabó por rechazar el subsidio (casos de Manresa y Torroella). Por fin, otras veces la negociación debió quedar en tablas, por lo que las villas no dieron ni un sueldo más de lo que les correspondía como questia ordinaria, haciendo caso omiso del subsidio ${ }^{22}$.

Así pues, cada vez que se pedía una questia/subsidio, se abría un proceso negociador en el que las villas francas y aquellas otras que tenían la questia fijada se apresuraban a destacar procuradores a la corte para lograr algunas concesiones a cambio del subsidio que ofrecerían sponte. Con la misma diligencia, las villas no dotadas de franquicias también enviaban mensajeros, en este caso para obtener una remisión de las cantidades solicitadas, procurando negociar con habilidad el alcance del subsidio que el rey les pedía más allá de la questia ${ }^{23}$. Por tanto, cada año, los consejos de casi

\footnotetext{
${ }^{20}$ Reg. 543, fol. 127r. y reg. 541, fol. $175 \mathrm{v}$. Recordemos que, a cambio de los 60.000 s. con que la villa contribuyó a su recuperación de los condes de Pallars, Jaime II la declaró en 1315 franca de questia y subsidios (reg. 329, fol. 274v.; véase El "Llibre vermell" de L'Arbóç, estudio introductorio de R. Conde, Tarragona, 1991, doc. 16, p. 52-53).

${ }^{21}$ Desde 1329 , por su contribución a la redención del castillo de Mura, la ciudad de Manresa estaba exenta de questia y subsidio durante dos años (reg. 493, fols. 134r.-v.); los $10.000 \mathrm{~s}$. que ofrecieron libremente en 1330, el rey no volch reebre ne acceptar (Real Patrimonio, Maestro Racional, $n^{\circ}$ 634, fols. 29v.-30r.). Por lo que respecta a Torroella, era posesión de Elisenda de Montcada, a quien correspondía la questia (reg. 329, fol. 273v.).

${ }^{22}$ Así, la questia de Berga estaba fijada, por privilegio de Alfonso el Franco (1286) en 3.000 s.; aunque en 1314 Jaime II pidió rogando $10.000 \mathrm{~s}$. para sufragar el matrimonio de la infanta Isabel y amenazó veladamente a la villa con ejercer la compulsión pura y dura si no pagaban sponte, los regidores debieron mantenerse firmes y sólo aceptaron pagar los $3.000 \mathrm{~s}$. de questia (reg. 327, fols. 155r.-162v.). Lo mismo cabe decir de Vilafranca del Penedès: exentạ de questia durante siete años desde 1312 por su contribución a la compra que hizo el rey de la jurisđicción a los castlans del lugar, en 1314, Jaime II les pidió rogando $30.000 \mathrm{~s}$., que la villa se negó a pagar, exhibiendo el correspondiente privilegio de exención (véase la questia/subsidio de 1314 en reg. 327, fols. 155r.-162v.).

${ }^{23}$ Aunque la cuestión es merecedora de una investigación más reposada, parece que la administración real tenía sumo interés en fomentar la llegada anual de los procuradores urbanos para solicitar una remisión de la questia/subsidio. Una luminosa documentación procedente de Cervera y perteneciente a los años 1337-1338 permite observar que la venida de los síndicos de prácticamente todas las villas de Cataluña suponía una considerable fuente de ingresos suplementarios para determinadas categorías de funcionarios regios: en efecto, los procuradores
} 
todos los núcleos urbanos de realengo debían reunirse para decidir las acciones a llevar a cabo, una vez que se había presentado el temido porter real a pedir el subsidio; para elaborar y fundar cuidadosamente los argumentos adecuados a fin de obtener una remisión o negociar contrapartidas (en el caso de las villas exentas) a cambio del subsidio; para nombrar procuradores y enviarlos con instrucciones muy precisas allá donde se encontrase la corte; para seguir de cerca las gestiones de éstos, etc. Todo ello, vuelvo a repetirlo, debió fomentar la adopción de iniciativas importantes en la vida de las villas, que repercutirían al cabo en su propia vertebración institucional. Por otra parte, no es preciso recordar hasta qué punto el pago anual de la questia real dinamizaría los resortes fiscales y financieros de las universidades ${ }^{24}$.

\section{LAS QUESTIE/SUBSIDIOS ENTRE 1309 Y 1359}

Una vez observadas las características de las questie/subsidios y las probables consecuencias que su exigencia tuvo en el desarrollo fiscal e institucional de las villas, veamos un poco más de cerca la evolución de esas peticiones durante el período considerado, en el que distinguiremos cuatro etapas fundamentales.

\section{La "edad de oro" de las questie/subsidios (1309-1333)}

Es en este período donde se aprecian con mayor claridad los fenómenos derivados de la dualidad entre questia obligatoria y subsidio negociado. Es también en esta etapa - a la espera de saber cómo sucedieron las cosas desde la segunda mitad del s. XIII- donde se puede observar más claramente la peculiaridad del subsidio, esto es, la cantidad suplementaria a la questia: como veremos seguidamente, en todas las cartas de petición se aducía siempre una causa concreta para justificar y legitimar la ayuda que el

distribuían dinero entre porters, macips, escribanos y todas aquellas personas que pudiesen allanarles el camino o acelerar las gestiones en el proceloso procedimiento administrativo; cf. M. SÁNCHEZ, Fiscalidad real y villas en Cataluña, cit. No olvidemos, además, que la entrega de las cạrtas de remisión suponía también una importante fuente de ingresos para la cancillería: por ejemplo, a tenor del $2,5 \%$ de la cantidad perdonada, que se había que pagar en concepto de tasas de cancillería, ésta pudo obtener casi $3.900 \mathrm{~s}$. en la petición de la questia/subsidio de 1329 y unos $4.500 \mathrm{~s}$. en la de 13330. Naturalmente, todos estos gastos representaban una gravosa carga para el municipio; por ejemplo, el de Cervera empleó cerca de $4.000 \mathrm{~s}$. en 1338 y 1339 en sufragar las mensajerías enviadas para obtener la remisión del subsidio.

${ }^{24}$ No voy a insistir en esta cuestión, de sobra conocida; véanse, por ejemplo, M. SÁNCHEZ; P. ORTí, La Corona en la génesis del sistema fiscal en Cataluña, cit. , p. 236-242; M. TURULL El naixement de la fiscalitat municipal a Lleida (1149-1289), cit.; y P'. ORTÍ, La construcció del sistema fiscal municipal a Barcelona, segles XIII-XIV, "Barcelona. Quaderns d'història", 2/3 (1996), p. 17-34. 
monarca pretendía obtener más allá de aquel tributo ${ }^{25}$. Por ello mismo, el período sería merecedor de un estudio detallado con el fin de observar, villa por villa, las incidencias de cada petición. En aras de la brevedad, nos limitaremos aquí a apuntar algunos de los rasgos más sobresalientes del tributo en los primeros treinta años del s. XIV.

Durante este tercio de siglo, se pidieron 21 questie/subsidios a las villas catalanas: 15 entre 1309 y 1327 (época de Jaime II); y seis entre 1327 y 1333 (reinado de Alfonso el Benigno). Veámoslas un poco más de cerca para apreciar su cadencia y, sobre todo, las causas aducidas por la Corona en cada ocasión.

El período debuta con las peticiones realizadas por Jaime II a principios de noviembre de 1309, cuando el monarca mantenía un largo, duro y, a la larga, infructuoso asedio a la ciudad nazarí de Almería ${ }^{26}$. Puesto que este subsidio se percibiría a lo largo de 1310 , la nueva petición no tuvo lugar hasta el primero de noviembre de 1311; en este caso, la causa aducida parece guardar una estrecha relación con la anterior: se trataba ante todo de saldar las deudas contraidas por el monarca con los nobles y caballeros que probablemente le habían acompañado a Almería ${ }^{27}$.

Tras los subsidios de 1309 y 1311, motivados por la expedición a tierras nazaríes y sus consecuencias, los tres siguientes fueron pedidos para sufragar los matrimonios de las infantas y del propio Jaime II. Así, a principios de junio de 1312, la causa fue el matrimonio de las hijas del rey Constanza y María $^{28}$. Justo un año después, el motivo fue el matrimonio de

${ }^{25}$ Es ocioso recordar que, por idénticas causas que a las villas del Principado, se pidieron subsidios a las villas aragonesas y valencianas, a lás aljamas de judíos y musulmanes, y, en algunos casos, también a Tos establecimientos eclesiásticos de la Corona.

${ }^{26}$ En la carta de petición se decía que la campaña almeriense redundaba en la gloria de Dios, en la exaltación de la fe cristiana, en el honor del rey y en la ampliación del territorio catalanoaragonés. Se resaltaba también el hecho de que el rey en persona acudiese ante los muros de Almería y se ponderaban, sobre todo, los gastos generados por la expedición. Por fin, teniendo en cuenta que la campaña no había resultado tan fácil como al principio se pensaba y que la capacidad del tesoro real no bastaría para sufragarla "neque nostre camere facultates ad supplementum expensarum huiusmodi comodo possent sufficere"), el rey decidió ex necessitate pedir un subsidio a sus hombres, subsidio del que serían excusados si sufferrent negocia (reg. 326 fols. $11 \mathrm{r}$. y $14 \mathrm{r}$.). Es sabido que, tras la victoria sobre los nazaríes a finales de agosto de 1309 , el sitio de Almería se prolongaría hasta finales de enero de 1310; por tanto, la petición del subsidio coincidió con el punto culminante del asedio; véase A. GIMENEZ SOLER, El sitio de Almería en 1309. Barcelona, 1904; y más recientemente, C. Ma MARUGÁN VALLVE, El sitio de Almería de 1309: el desarrollo de la campaña militar, en Almería entre culturas (siglos XIII-XVI), I, Almería, 1990, p. 171-188.

${ }^{27}$ Según la petición, era necesario saldar las deudas para evitar toda ocasión de escándalo en el territorio catalanoaragonés; por tanto, "in tam validis necessitatibus nostris", el rey requería la ayuda de sus súbditos. Y, como en el caso anterior, les liberaría de la obligación de pagar si los asuntos no lo requerían o hubiese dinero suficiente en el tesoro real ("si sufferrent negocia vel in camera nostra habundaret peccunia...") (reg. 326, fol. 70r.)

${ }^{28}$ María, hija de Jaime II y de Blanca d'Anjou, contrajo matrimonio en enero de 1312 con el infante Pedro, hermano de Fernando IV de Castilla. La infanta Constanza, por su parte, casó en junio de 1312 con Don Juan Manuel. En la carta de petición se decía que el subsidio serviría tanto para pagar el ajuar de ambas infantas como para sufragar los gastos de las ceremonias; en estas circunstancias, "expediat nos auxilium postulare" (reg. 326, fol. 126r.). Sabemos que el monarca 
la infanta Isabel con Federico el Hermoso, duque de Austria y Estiria e hijo del emperador Alberto ${ }^{29}$. Y, por fin, a principios de febrero de 1316, la causa fue el matrimonio de Jaime II con María de Lusignan $^{30}$.

Después de los matrimonios, llegó el turno a los subsidios pedidos por razones patrimoniales. Los solicitados en mayo de 1317, en junio de 1318 y en septiembre de 1320 lo fueron para ayudar al monarca en la compra del condado de Urgell y del vizcondado de Àger ${ }^{31}$. Y el solicitado en julio de 1319 lo fue para devolver los préstamos concertados para pagar una deuda al rey Sancho de Mallorca, por la cual se habían hipotecado las potestats del reino de Mallorca y de los restantes territorios de esa Corona que eran tenidos en feudo del soberano catalanoaragonés; a todo ello debía añadirse lo debido al rey mallorquín por la recuperación del valle de Arán $^{32}$.

Después de 1321, en que el monarca solicitó un nuevo subsidio, motivado simplemente pro utilitatibus et necessitatibus nostris et regni ex diversis et arduis causis et negociis nobis inminentibus... ${ }^{33}$, las peticiones comprendidas entre 1322 y 1325 lo fueron para hacer frente a los gastos generados por la conquista de Cerdeña. Como he mostrado en otro lugar, los

tuvo serias dificultades para satisfacer las dotes de ambas infantas y que el pago se demoró largo tiempo (véase J.-E. MARTínEZ FERRANDO, Els fills de Jaume II, Barcelona, 1950, p. 61-68 y 103 117).

${ }^{29} \mathrm{El}$ matrimonio por poderes tuvo lugar en la catedral de Barcelona en octubre de 1313 y las bodas definitivas se celebraron en Ravensburg, en abril de 1315; cf. MARTíNEZ FERRANDO, Els fills de Jaume II, cit., p. 137-147. El motivo concreto aducido en este çaso fue la necesidad de devolver los préstamos contraidos para atender a los gastos del matrimonio (reg. 327, fol. 155r.).

30 “...cum racione matrimonii...fecerimus plurimas et diversas expensas pro quibus convenit nos a nostris fidelibus auxilium postulare..."(reg. 327, fol. 198r.). Hermana de Enrique II de Chipre, María era heredera de las coronas de Chipre y de Jerusalén. Después de una larga espera, el matrimonio se celebró en Gerona, probablemente a mediados de 1315 ; véase J.-E. MARTínEZ FERRANDO, Jaume II o el seny catala. Alfons el Benigne, Barcelona, 1963, p. 215-224.

${ }^{31}$ Recordemos que Ermengol de Cabrera, XVI conde de Urgell, había dejado dispuesto en su testamento la venta del condado de Urgell y del vizcondado de Ager a la Corona, con la expresa condición de que el infante Alfonso (futuro rey) contrajese matrimonio con Teresa d'Entença, sobrina de Ermengol. Muerto éste en 1314, Jaime II se apresuró a comprar aquellos territorios a los albaceas de Ermengol por 100.000 1. jaquesas, más 15.0001 . barcelonesas que se entregarían a Fahida, viuda del conde, en concepto de dote. Se pagaron al contado a los albaceas $10.000 \mathrm{lj}$. y se prometió abonar el resto en nueve años, a razón de 10.000 lj. anuales. No fue fácil el pago de estas importantes cantidades, sobre todo, la dote de Fahida, quien llegó a protestar por ello ante el papa Juan XXII; véanse DIEGO DE MONFAR, Historia de los condes de Urgell, en P. DE BOFARULL, Codoin ACA, X, Barcelona, 1853, p. 45-69; y MARTÍNEZ FERRANDO, Jaume II, cit. p. 285-287. En las tres cartas de petición se decía que la compra de esos territorios se había hecho "pro utilitate publica et ad bonum statum specialiter Catalonie ad amplificacionem et fortificacionem dominacionis nostre ."; se decía también que el subsidio era necesario para desembargar los castillos y lugares obligados a los albaceas del conde de Urgell (reg. 327, fols. 228 r. y reg. 328, fols. 36r. y 104r.).

${ }^{32}$ Todas esas razones justificaban la petición del subsidio ("hiis de causis subsidium vestrum et aliorum fidelium nostrorum necessarium habeamus...") (reg. 328, fol. 72r.). Por el tratado de Poissy (abril de 1313), Jaime II recuperaba el valle de Árán, que permanecía secuestrado por el rey de Mallorça desde el tratado de Anagni, y se comprometía a pagar a Sancho de Mallorca los gastos de administración del valle durante el largo secuestro; la deuda ascendía a 7.000 lb., que serían pagadas en dos plazos durante el próximo trienio. Véanse J. REGLÀ, Francia, la Corona de Aragón y la frontera pirenaica, Madrid, 1951, p. 173-195; y J.-E. MARTÍnEZ FERRANDO, La tràgica historia dels reis de Mallorca, Barcelona, 1960, p. 155-158.

${ }^{33}$ Reg. 328, fol. 132r. 
subsidios pedidos entonces, no sólo a las villas sino también a las ciudades exentas de questia, supusieron un importante punto de inflexión en la evolución de la fiscalidad real sobre los núcleos de realengo ${ }^{34}$. Así, en septiembre de 1322, Jaime II pedía una questia/subsidio a las villas, ponderando, entre otras cuestiones, la importancia de la conquista de Cerdeña (ad exaltacionem Corone nostre et domus, ad augmentacionem et amplificacionem felicium palmitum regni nostri et ad magnum comodum subditorum...), y recordando a los dirigentes urbanos que ya había obtenido un cuantioso auxilio voluntario (sponte) de los eclesiásticos y de las ciudades exentas de questia $^{35}$. Pero las principales novedades ocurrieron en 1323 cuando, ante la defección de la nobleza y de la Iglesia, el brazo real ofreció en las Cortes de Barcelona un servicium bastante original en el contexto fiscal de la época. Para obtenerlo se estableció un doble impuesto: uno de capitación, consistente en el pago de un sueldo anual durante los dos años que duraría el servicium; y otro, moderadamente diferenciado, sobre los bienes muebles e inmuebles ${ }^{36}$. Ahora bien, tres meses después de ordenarse el subsidio, resultó que las cantidades recaudadas eran tan exiguas que no alcanzaban la cifra que las villas solían pagar como questia ordinaria. Ante unas perspectivas tan poco halagüeñas, se decidió que los recaudadores se limitasen a cobrar, como mínimo, las mismas cantidades que las universidades habían pagado como questia el año 1322. Todo ello significa que las grandes expectativas puestas en un donativo bienal tan complejo como minuciosamente regulado quedaron reducidas a la percepción de dos simples questie, una en 1324 y otra en 1325, ambas idénticas a la recaudada en 1322 . Y ello muestra también que la questia siguió sirviendo de módulo a la fiscalidad extraordinaria durante el primer tercio del s.XIV.

Como he apuntado más arriba y mostrado con más detalle en otros lugares, los subsidios de 1322 y 1323 me parecen de importancia capital en la historia de la fiscalidad real y municipal. Por un lado, fue la primera vez que las ciudades y villas de Cataluña otorgaron una ayuda negociada con el rey en una asamblea conjunta. Y, por otro lado, fue en 1322 cuando las grandes ciudades del Principado (Barcelona, Lérida, Tarragona, Tortosa)

\footnotetext{
${ }^{34}$ Véase M. SÁNCHEZ, Contributi finanziari di città e ville della Catalogna alla conquista del regno di Sardegna e Corsica (1321-1326), "Medioevo. Saggi e Rassegne", 20, 1995, p. 317352 .

${ }^{35}$ Reg. 329, fol. 151 r. y artículo citado en la nota anterior, p. 326-327.

${ }^{36}$ Dada las características de ambos impuestos, se ordenó realizar los correspondientes recuentos de fuegos y manifests de los bienes de cada habitante. Que sepamos, no ha llegado hasta nosotros ningún ejemplar de esta documentación tan importante para conocer la población y el nivel de riqueza de las ciudades y villas de realengo en una época tan precoz, desde este punto de vista, como 1323: ¿no llegaron a confeccionarse, como parece probable dado el resultado final del servicium, o fueron destruidos por el fuego una vez saldado el subsidio, tal y como se prescribía en uno de los capítulos de su concesión?. Véase el texto de este servicium en M. SÁNCHEZ; P. ORTÍ, Corts, Parlaments i fiscalitat, cit., doc. V. p. 33-47; y sobre las Cortes de Barcelona y los resultados de este donativo, M. SÁNCHEZ, Contributi finanziari, cit., p. 327-336.
} 
empezaron a reunir los subsidios al rey mediante impuestos indirectos (imposicions). Pero el escasísimo rendimiento del servicium de 1323 tuvo también hondas consecuencias de cara al futuro: así, el procedimiento utilizado para obtener el subsidio de 1323 - un doble impuesto de cuotasería abandonado diez años después para ser sustituido por donativos de repartición; en consecuencia, a partir de 1333, acabaría por triunfar el método que se venía usando para percibir las questie: asignar una cantidad a cada lugar y dejar que la comunidad lo obtuviese bien a través de tallas o, desde 1340, de imposicions. Por otra parte, hasta 1359 no se volvería a establecer en Cataluña un impuesto directo de carácter general y así toda la fiscalidad extraordinaria negociada en Cortes y Parlamentos durante las décadas de 1340 y 1350 reposaría básicamente sobre las imposicions.

Pero, sigamos con nuestro hilo cronológico. De todo lo dicho se deduce que, con el pretexto de la conquista de Cerdeña, el rey percibió una questia en 1322 y un servicium en 1324-1325, reconvertido en sendas questie; por tanto, la Corona obtuvo de hecho tres questie $(1322,1324$ y 1325), las tres sensiblemente parecidas por lo que respecta a su volumen. Mientras a principios de 1326 todavía se estaban percibiendo con dificultades ciertos atrasos en el pago del servicium, Jaime II solicitó otra questia/subsidio a las villas aduciendo en esta ocasión causas generales ${ }^{37}$. Al año siguiente (1327), la razón esgrimida fue la disminución de los ingresos de la casa real debidos a los gastos generados por la campaña sarda y otras necesidades ${ }^{38}$.

En junio de 1327, es decir, muy pocos meses antes de la muerte de Jaime II, por una nota de carácter interno contenida en el correspondiente registro de cancillería, sabemos que tanto las questie de Cataluña como las peite de las villas valencianas habían sido fijadas en unas cantidades precisas. Según la breve nota que encabeza la relación de villas, cuando se impusiesen questie, deberían exigirse las cantidades escritas al margen de cada villa, salvo en el caso de que, por una causa concreta, el monarca quisiese un subsidio mayor; y que, de esas cantidades, se haría una remisión de la mitad y la otra parte sería percibida por la corte ${ }^{39}$. Creo que en este escueto texto - escrito, no lo olvidemos, para uso interno del personal de la cancillería a guisa de instrucciones para saber a qué atenerse cuando se exigiesen questie - queda perfectamente de manifiesto la diferencia entre una questia fija y un subsidio

\footnotetext{
37 “..exigentibus causis multis, necessarium nobis est...a nostris fidelibus questias exigamu...."Vale la pena decir que, por primera vez en la época que consideramos, aparece la cláusula causa cessante: el rey cancelaría la questia si desaparecian las causas que habían motivado su petición (reg. 329, fol. 237r.)

${ }^{38}$ También en este caso, los súbditos serían excusados de pagar el tributo "si premisse compulsive cause cessarent" (reg. 329, fol. 269r.).

39" Certum est quod dominus rex nunc mense iunii anni presentis MCCCXX septimi taxavit subscripta loca Cathalonie ad quantitates subscriptas, quas ordinavit eis imponi futuris annis quando questie imponentur nisi contingerit ex casu seu casibus eum velle augere ipsas quantitates; et quod de ipsis quantitatibus fiat remissio medietatis et reliqua medietas curie persolvatur" (reg. 329 , fol. 266r.).
} 
superior a aquella, que el monarca podía pedir ex casu seu casibus. Además, parece que el breve y sibilino texto nos levanta un poco el velo que cubre el mecanismo de la negociación. Aunque ello requeriría una investigación más reposada, es posible que, debido a la experiencia de 1323, el rey pretendiese fijar las cantidades mínimas, de las que no se debería bajar un sueldo, que cada villa debería pagar como questia, mientras que podría negociarse la remisión de una parte de la cantidad suplemementaria, esto es, el subsidio.

Jaime II murió el 2 de noviembre de 1327, sucediéndole en el trono el infante Alfonso, conde de Urgell. De cara a su solemne coronación en Zaragoza, que tendría lugar en la Pascua de Resurrección de 1328, el nuevo monarca solicitó un subsidio a las villas ya en diciembre de $1327^{40}$. Al año siguiente, el subsidio fue solicitado (octubre de 1328) para el matrimonio que habría de celebrar Alfonso el Benigno con la infanta Leonor de Castilla a principios de febrero de $1329^{41}$.

Por fin, el resto de los subsidios solicitados durante el breve reinado de aquel monarca tuvieron como causa fundamental la financiación de la cruzada organizada contra el sultanato nazarí, simple reedición del viejo proyecto que llevó a Jaime II a las puertas de Almería; de esta forma, el ciclo que estamos analizando se abre (1309) y se cierra (1333) con sendas questie/subsidios para la guerra contra los granadinos ${ }^{42}$. Con destino a la proyectada - y siempre aplazada - campaña contra la frontera oriental del sultanato nazarí, el rey Alfonso pidió cuatro subsidios a las villas catalanas: en noviembre de 1329 , en septiembre de 1330 , en enero de $1332^{43}$ y en el mismo mes de 1333, con la finalidad de preparar una armada contra nazaríes y genoveses ${ }^{44}$.

Así pues, entre 1309 y 1333, los monarcas Jaime II y Alfonso el Benigno solicitaron 21 subsidios a las villas catalanas, con periodicidad

\footnotetext{
40 "Subsidium rogando postulatum...racione coronacionis et milicie...ab universitatibus Cathalonie tam illis videlicet quibus questie consueverunt imponi quam aliis quibusdam..." (reg. 543 , fol. 2r.). Apenas parece necesario decir que las cantidades inicialmente pedidas a las villăs eran muy superiores a las tasadas por Jaime II pocos meses antes. A la coronación del rey en Zaragoza dedicó unas memorables páginas Ramọn Muntaner al final de su crónica ( $R$. MuNTANER, Crònica, caps. 294-298, ed. F. Soldevila, Barcelona, 1971, p. 934-943).

${ }^{41}$ "Subsidium postulatum pro felici matrimonio domini regis" (reg. 543, fol. 29r.). Las cantidades exigidas fueron practicamente las mismas que las pedidas para el subsidio de la coronación.

${ }^{42}$ Sobre la cruzada de Alfonso el Benigno, véanse, por citar sólo dos trabajos, M. SÁNCHEZ, La Corona de Aragón y el reino nazarí de Granada durante el siglo XIV: las bases materiales y humanas de la cruzada de Alfonso IV (1329-1335), tesis doctoral, Barcelona, 1974; y $\mathrm{M}^{\mathrm{a}} \mathrm{T}$. FERRER MALLOL, La frontera amb l'Islam en el segle XIV. Cristians i sarraïns al País Valencià, Barcelona, 1988, p. 125-137.

${ }^{43}$ Este subsidio, en el que, según anotación del correspondiente registro, se respetaría lo ordenado por Jaime II en 1327, fue solicitado "exigentibus causis multiplicibus" (reg. 543, fol. 165r.). Aunque no se dice expresamente que su destino fuese la cruzada, es difícil pensar que, entre las causas aducidas, no se encontrase el proyecto que orientó gran parte del reinado de Alfonso el Benigno.

${ }^{44}$ Sobre todos estos subsidios, véase M. SÁNCHEZ, "Questie” y subsidios, cit.
} 
prácticamente anual. Vuelvo a repetir que todos ellos funcionaron según el particular mecanismo de las questie/subsidios. Como es bien sabido, la reflexión teológica de la época permitía a los soberanos pedir un subsidio extraordinario (en nuestro caso, una cantidad suplementaria a la questia ordinaria), siempre que se adujese una causa finalis que estuviese dirigida al bien común y a la satisfacción de las necesidades públicas. En este sentido, el cuidadoso análisis de las cartas circulares de las distintas peticiones nos permitirían -y es una cuestión que me reservo para un futuro trabajodescubrir los nexos entre las causas invocadas en cada caso por los monarcas catalanoaragoneses y lo prescrito en los textos de teólogos, canonistas y juristas. De todas formas, basta una superficial lectura de dichas cartas para observar que los motivos aducidos para legitimar los subsidios coinciden a grandes rasgos con los que se contienen en aquellos textos o con los que estaban permitidos por el derecho feudal de la época. Así, hubo subsidios justificados por la guerra contra los musulmanes $(1309,1311,1329,1330$, 1332 y 1333); por el matrimonio del rey y de las infantas $(1312,1314,1316$ y 1328); por la coronación y recepción de la caballería del nuevo soberano (1328); y por la adquisición de nuevos territorios, que ampliaban el patrimonio real: subsidios de 1317, 1318 y 1320 para la compra del condado de Urgell; de 1319 para la incorporación del valle de Arán; o de 1322, 1324, 1325 y 1327 para la conquista de Cerdeña. Por fin, si no se aducía una causa concreta, se invocaban los grandes gastos realizados pro utilitatibus et necessitatibus nostris et regni (como en 1321) o exigentibus causis multis (como en 1326): en ambas ocasiones, el monarca consideraba justificado pedir una ayuda a sus súbditos (nos conveniat a vobis subsidium postulare $)^{45}$. Como ya he apuntado, se observa también, desde 1309 y mucho más claramente desde 1326, la aparición de la cláusula cessante causa, según la cual, el subsidio quedaría sin efecto - cosa que nunca sucedió, por otra parte- si desaparecía la causa que lo había motivado ${ }^{46}$.

Por lo que respecta a las villas implicadas, la petición de estos 21 subsidios en el período de 24 años debió tener consecuencias muy importan-

${ }^{45}$ La bibliografía sobre el particular es relativamente copiosa. Baste citar los siguientes trabajos, todos ellos con abundantes referencias bibliograficas: R. POMINI, La "causa impositionis" nello svolgimento storico della dottrina finanziaria (1950), reimp., Milano, 1972; E.A.R. BRown, Customary Aids and Royal Finance in Capetian France. The marriage aid of Philip the Fair, Cambridge, Mass., 1992, especialmente las p. 35-69; y E. ISENMANN, Les théories du Moyen Age et de la Renaissance sur les finances publiques, en R. Bonney (dir.), Systèmes économiques et finances publiques, Paris, 1996, p. 3-35. Para el caso catalanoaragonés y, sobre todo, acerca del papel de Ramon de Penyafort en el desarrollo de la "causa impositionis", véase T. DE MONTAGUT, La recepció del dret tributari comú a la Corona d'Arago, en El territori $i$ les seves institucions historiques, Barcelona, 1999, p. 361-383.

${ }^{46}$ En 1326: “si cause cesșarent, vos libenter excusaremus; y en 1327 y 1332: si premisse compulsive cause cessarent..." Sobre esta cuestión, véase E.A.R. BROWN, "Cessante causa" and the taxes of the Last Capetians: the political Applications of a Philosophical Maxim, "Studia Graciana", 15, Roma, 1972, p. 567-587 (reimp. en E.A.R. BROWN, Politics and Institutions in Capetian France, Variorum reprints, 1991). 
tes, que habría que estudiar con detalle villa por villa y subsidio por subsidio. De entrada, y como dije más arriba, el particular mecanismo de la questia/subsidio debió movilizar en no pocas ocasiones a los procuradores de cada villa para acudir a donde estuviese la corte y negociar el alcance de la cantidad suplementaria a la questia ordinaria. En segundo lugar, el pago de esos 21 subsidios se materializaría en el establecimiento frecuentísimo de tallas diferenciadas para pagarlos; y, al mismo tiempo, impulsaría a muchos municipios a solicitar créditos para satisfacer inmediatamente las peticiones del monarca. Con todo ello queremos decir hasta qué punto las exigencias regias afianzarían y perfeccionarían los engranajes fiscales y financieros de cada comunidad. Como he dicho al principio, la casi general carencia de documentación municipal para esta época puede suplirse parcialmente con el material procedente de la cancillería real, tanto con el que venimos utilizando como con el de otras series de registros. Y en aquellos afortunados casos en que se haya conservado alguna documentación municipal para estos remotos años, apenas parece necesario subrayar el interés que tendría poner en relación sus datos con los suministrados por la cancillería real que acabamos de comentar.

\section{Questie/subsidios, Cortes y Parlamentos (1334-1340)}

Este breve período es capital en la evolución de las questie/subsidios y, por ello mismo, también debería ser investigado con más profundidad de lo que podemos hacer aquí. Digamos ya que, durante estos seis años, se empezó a romper el vínculo de la questia con el subsidio. En otras palabras, mientras los subsidios -debidamente justificados con la adecuada causa finalis - serían negociados en asamblea con los procuradores urbanos, la questia inició el camino hacia su condición de simple tributo de carácter señorial percibido por el monarca en algunas - cada vez menos- villas del Principado. Este proceso se inicia precisamente en el período que vamos a considerar, a través de una serie de ensayos que, por su carácter hasta cierto punto experimental, son bastante complejos y requerirían un análisis más pausado.

Los cambios se iniciaron en las Cortes de Montblanc (1333), reunidas por Alfonso el Benigno con el fin de solicitar ayuda contra la coalición granadino-genovesa. Puesto que ya nos hemos ocupado de la importancia de esta asamblea en alguna que otra ocasión, me limitaré aquí a recordar las cuestiones más directamente relacionadas con nuestro tema ${ }^{47}$. Después de cosechar un nuevo fracaso en su intento de obtener un donativo general de los tres brazos, el rey convocó a los procuradores de todas y cada una de las

\footnotetext{
${ }^{47}$ Véase, por ejemplo, M. SÁNCHEZ; P. ORTí, La Corona en la génesis del sistema fiscal municipal, cit., p. 247-253.
} 
villas que pagaban questia (desde Manresa o Cervera hasta Sedó/Riber o Almacelles) para solicitar un subsidio con que financiar la guerra contra Génova y Granada. Fue la primera vez que acudieron a una asamblea representantes de todo el realengo y no sólo de las ciudades y de las villas principales como venía siendo habitual. A resultas de este encuentro, se votó un subsidio bienal que estaría en vigor desde septiembre de 1333 hasta el mismo mes de 1335. A la vista de los escasos rendimientos del doble impuesto de cuota de 1323, se procedió a repartir entre todas las comunidades las 10.000 l. votadas, utilizando como criterio del reparto la cantidad que dichos lugares acostumbraban a pagar como questia ${ }^{48}$. Pero lo más interesante para nuestro objetivo es que una parte del subsidio lo recibiría el rey en concepto de questia ordinaria, mientras otra porción - el subsidio propiamente dichosería recaudada por unos clavaris elegidos por Barcelona y encargados de gestionar la ayuda. En realidad, lo que se hizo en 1333 fue negociar una questia/subsidio conjuntamente con todo el realengo, en lugar de hacerlo por separado con cada una de las villas; como resultado, la questia propiamente dicha sería ingresada por el rey y recaudada por porters regios, mientras la cantidad suplementaria a aquella - el subsidio- sería entregada a los clavaris encargados de administrar el donativo ${ }^{49}$.

Otra cuestión importante del subsidio de Montblanc radica en el hecho de que se autorizaba a cierto número de villas - precisamente a las que celebraban mercado - a reunir la cantidad que les correspondía en dicho subsidio mediante imposicions. Como hemos apuntado repetidas veces, ello es un dato de primer orden para la geografía económica del realengo catalán en el primer tercio del s. XIV, puesto que se relaciona un número relativamente elevado de importantes centros de mercado, capaces, por tanto, de obtener el subsidio mediante impuestos indirectos. Aunque la lista es suficientemente conocida, no está de más volver a repetirla en un coloquio dedicado precisamente a las villas catalanas ${ }^{50}$ : Cervera (54.000 s.), Manresa, Vilafranca, Montblanc, Tàrrega/Vilagrassa (30.000 s. cada una), Vic, Piera, Camprodon (10.000 s. cada una), Caldes de Montbui (9.000 s.), Sarral (6.750 s.), Santpedor, Igualada, Besalú, Torroella (6.000 s. cada una), L'Arbóç $(5.000$ s.), Figueres $(3.000$ s.) y Granollers (1.800 s.). Por otra parte, tal y como correspondía a un subsidio negociado, los regidores de esas villas-

\footnotetext{
${ }^{48}$ Sobre esta cuestión véase P. ORTí Gost , La distribución de la carga fiscal entre las ciudades y villas de realengo en la Cataluña del siglo XIV, en D. MENJOT; M. SÁNCHEZ, Fiscalidad de Estado y finanzas municipales en los reinos hispánicos, Casa de Velázquez, Madrid, 2006, p. 275-316.

${ }^{49}$ En la cancillería eran plenamente conscientes de estas novedades: cuando, a principios de 1334, el rey solicitó la questia al realengo, se decía a los recaudadores que "de presenti dictas questias sub forma solita non duximus exigendas" (reg. 543, fols. 230r.-v.).

${ }^{50} \mathrm{He}$ ordenado las ciudades y villas que obtuvieron permiso para establecer imposicions según las cantidades que les fueron repartidas en este subsidio. No aparece Barcelona, cuya contribución consistió en el armamento de 10 galeras cada año.
} 
mercado tenían plena capacidad para arrendar las imposicions, promulgar bans para controlar el impuesto y evitar los fraudes, y percibir las multas por su incumplimiento; además, tendrían también la potestad para aumentar o disminuir las imposicions si observaban que su producto no bastaría o sobrepasaría a la cantidad que les había sido repartida en el subsidio ${ }^{51}$.

No hace falta insistir en la relevancia de este donativo en la evolución fiscal e institucional de las villas catalanas, empezando porque todas ellas - hasta las más minúsculas - enviaron sus procuradores a Montblanc y estuvieron representadas por primera vez en una asamblea. Pero, sobre todo, la posibilidad de reunir el subsidio mediante imposicions debió obligar a las villas-mercado a organizar una más o menos compleja maquinaria administrativa para establecer las imposicions, subastarlas, gestionar su producto y canalizar una parte hacia la corte como questia y otra porción a los clavaris nombrados por Barcelona. Por tanto, observamos de nuevo cómo las exigencias de la monarquía continuaban provocando transformaciones relevantes en el paulatino proceso de consolidación de la fiscalidad munici$\mathrm{pal}^{52}$.

La experiencia de 1333-1335 no tuvo continuidad inmediata. El nuevo soberano Pedro el Ceremonioso pidió sendas questie/subsidios a la antigua usanza en 1336 y $1337^{53}$.

Pero, en 1338, la necesidad de defender a la Corona de las amenazas mariníes obligó al monarca a convocar un Parlamento en Barcelona con los representantes de las principales villas reales; como resultado de esta asamblea, el Ceremonioso obtuvo un subsidio en la misma línea que el otorgado a su antecesor en Montblanc cinco años antes ${ }^{54}$. En efecto, en abril y mayo de 1338, se votó una ayuda bienal (1338-1340), cuyo destino, como en 1333, sería doble: una parte iría a parar al rey en concepto de questia y otra parte sería recaudada por Bernat Guillem Sabastida, quien, en calidad de financiero al servicio de la Corona, buscaba prestamistas o adelantaba él mismo el dinero necesario para la guerra contra los musulmanes. Así,

\footnotetext{
${ }^{51}$ Véase el donativo de Montblanc en M. SánchEZ; P. ORTí, Corts, Parlaments i fiscalitat, cit., doc. VI, p. 49-62; y el reparto de la porción correspondiente al rey como questia en M. SÁNCHEZ, "Questie" y subsidios, cit., p. 28-30, 45 y 53.

${ }^{52}$ No es extraño que todo ello se refleje en el aumento y diversificación del material documental generado por algunos municipios. No parece casual, por ejemplo, que el primer libro de clavaria de Cervera date de estos años; cf. M. TURULL, La hisenda l el sistema financer de la Paeria de Cervera. Els ingressos del consell (1331-1333), "Ilerda", XLVII, 1986, p. 443-478.

${ }^{53} \mathrm{El}$ solicitado en febrero de 1336 lo fue por tres motivos: "pro felici coronacionis et milicie..."; "pro exequenda ultimam voluntatem" de Alfonso el Benigno; y "pro resistendo pravis conatibus ăliquorum insistencium contra bonum statum Cathalonie" (reg. 1501, fol. 2r.). Y el de marzo de 1337 fue pedido - como los de 1326,1327 y $1332-$ - ex multiplicibus causis necessariis...", añadiendo, como era habitual, la cláusula cessante causa (reg. 1501, fol. 49r.).

${ }^{54}$ En diversas cartas se decía expresamente que el nuevo subsidio se percibiría como el de 1333 (reg. 1501, fols. 109r.-111r., 117r.-v. 122v.-123v. y 148v.-149r.). Esta ayuda cancelaba otras dos pedidas a las villas en enero de 1338 para el matrimonio del rey con María de Navarra y por "causas urgentes y necesarias" (reg. 1501, fols. 70r. y 84r.).
} 
mientras los porters regios ingresaban la parte correspondiente a la questia, el subsidio propiamente dicho fue asignado a Sabastida ${ }^{55}$. Por tanto, al igual que un lustro antes, las mismas villas-mercado (y algunas otras que se añadieron, como Berga, la batllia de Els Prats o Terrassa) pudieron volver a establecer imposicions durante dos años, profundizando así el camino iniciado en 1333.

Entre marzo y abril de 1339, el Ceremonioso convocó nuevamente a los procuradores urbanos para reunirse a principios de junio (primero en Barcelona, después en Ulldecona y definitivamente en la ciudad condal) con el fin de solicitarles una nueva ayuda para financiar el viaje del monarca a la curia pontificia ${ }^{56}$. Todavía no tengo constancia de la celebración de esta asamblea ni de las características del subsidio pedido, sobre todo, por lo que respecta a su posible semejanza - o no- con los de 1333 y 1338 . El hecho cierto es que, a finales de julio de 1339 (¿como resultado de aquel Parlamento?), el Ceremonioso pidió un nuevo auxilio racione certi numeri galearum quas armavimus...contra perfidum Marrochorum regem et eciam racione viagii quod facturi sumus ad dominum summum pontificem... ${ }^{57}$. Por fin, en marzo de 1340, se pidió una nueva questia/subsidio aduciendo otra vez "causas urgentes" 58 .

Así pues, aunque el estado actual de la investigación no permite afirmarlo con rotundidad, parece que durante el breve período considerado se solicitaron cuatro questie/subsidios (1336, 1337, 1339 y 1340) y dos donativos, en 1333 y 1338 , donde se marca muy claramente la diferencia entre la questia ordinaria del rey y el subsidio negociado en asamblea. No tardaría mucho en consumarse la ruptura definitiva durante el decenio de 1340.

\section{La disolución de la questia/subsidio (1340- c.1348)}

Hasta ahora hemos venido viendo cómo el subsidio iba adherido a la questia en tanto que cantidad suplementaria a ésta. Con más claridad hemos advertido esta particularidad en los donativos bienales de 1333 (Cortes de Montblanc) y de 1338 (Parlamento de Barcelona); en ellos, las villas pagaron en realidad una sola cantidad, aunque a dos agentes recaudadores diferentes:

\footnotetext{
${ }^{55}$ Véąse un somero análisis de este subsidio en M. SÁNCHEZ, Fiscalidad real y villas en Cataluña, cit.

${ }^{56}$ Reg. 1501, fols. 181r., 183r., 184r., y 197r.

${ }^{57} \mathrm{Reg}$. 1502, 93r. Al mismo tiempo, el rey revocaba otra demanda hecha en febrero de 1339 por "causas urgentes", demanda a todas luces ilegítima puesto que, en función del donativo bienal de 1338-1340, el monarca no podía hacer ninguna otra petición durante ese período; así se lo recordaron al Ceremonioso algunas villas (reg. 1501, fols. 173r. y 175v.-179r.). No obstante, el subsidio de julio de 1339 fue efectivamente recaudado, como lo muestra el albarán testimonial extendido al recaudador Bernat Riba (Real Patrimonio, Maestro Racional, $\mathrm{n}^{\circ} 637$, fols. $96 \mathrm{v},-98 \mathrm{v}$.). A la vista de estos datos, a veces un tanto contradictorios, parece evidente la necesidad de estudiar con más detenimiento los subsidios de estos años.

${ }^{58}$ Reg. 1502, fol. $108 \mathrm{v}$.
} 
una parte al porter real como questia y otra porción a los encargados de gestionar la ayuda. Se derivaba de lo anterior que, mientras duraba el donativo que había sido negociado en asamblea, las villas no pagaban específicamente questia, ya que ésta quedaba englobada en dicho donativo. Pero, con ocasión del ciclo fiscal de 1340, 1342 y 1344, en que las ciudades y villas otorgaron al rey tres grandes donativos para financiar la campaña del Estrecho de Gibraltar y posteriormente la guerra de Mallorca, se rompió definitivamente la dualidad questia/subsidio que nos ha acompañado desde $1309^{59}$. Dicho de otra manera, a partir de este momento, la presión fiscal sobre las villas sería mayor, puesto que, además de pagar los donativos otorgados en asamblea, deberían hacer frente anualmente a la questia ordinaria, si no estaban expresamente exentos de la misma ${ }^{60}$. Todo ello quiere decir que, a partir de la década de 1340, el binomio questia/subsidio había dejado de ser el vehículo principal por donde había transitado hasta entonces la fiscalidad real: de ahora en adelante, las cantidades más consistentes para financiar las guerras de la Corona se obtendrían en las grandes asambleas de Cortes y Parlamentos, mientras la cada vez más fosilizada questia quedaba relegada al rango de un modesto tributo que el rey tenía el derecho a percibir sólo en determinados lugares. Parece significativo que, desde 1344 hasta 1359, en que he detenido mi estudio, las anuales peticiones regias lo fuesen simplemente pro questia, sin más justificación: ya no tenía sentido desplegar una amplia retórica para legitimar un subsidio que el monarca obtenía por caminos diferentes. En todo caso, es en el bien articulado discurso (proposición) que el rey dirigía a los reunidos durante la primera sesión de las Cortes donde deberemos buscar a partir de ahora las causas que el soberano aducía en cada momento para justificar y legitimar los importantes donativos obtenidos de las asambleas ${ }^{61}$.

Desde otro punto de vista, bueno será recordar que, a partir de 1340, el monarca otorgó un permiso general para que todos los enclaves de realengo de Cataluña - y no sólo las ciudades y las villas-mercado- pudiesen reunir los donativos por medio de imposicions. Concluía así el proceso de extensión

\footnotetext{
${ }^{59}$ Sobre estos tres donativos, véanse M. SÁnCHEZ; P. ORTí, Corts, Parlaments i fiscalitat, cit., docs. VII, VIII y IX, p. 63-88; y de los mismos autores "La Corona en la génesis del sistema físcal municipal", cit., p. 254-260. Sobre los donativos de 1340 y 1342, véase M. SÁNCHEZ; S. GASSIOT La "Cort general" de 1340 y la contribución catalana a la guerra del Estrecho, en Les Corts a Catalunya. Actes del Congrès d'Història Institucional, Barcelona, 1991, p. 222-240.

${ }^{60}$ Así, en 1340 , a pesar de que en las Cortes de Barcelona el brazo real concedió un subsidio trienal, que duraria hasta 1343 , el rey pidió sus questie acostumbradas en diciembre de 1340, en el mismo mes de 1341 y en febrero de 1343 (reg. 1502 , fols. $125 \mathrm{v} ., 144 \mathrm{r}$. y 153r.). Más claramente se aludía a esta doble fiscalidad en sendos capítulos de los donativos de 1342 y 1344 : los síndicos aceptaron que el rey pudiese recibir questie de los lugares donde lo tenía por costumbre, aunque pidieron que sólo se les exigiese aquello que "han pagat el temps passat...ne més anant no'ls puxá ésser innovat" (cf. SÁNCHEZ; ORTÍ, Corts, Parlaments $i$ fiscalitat, doc. VIIII cap. 21 , p. 77 y doc. IX, cap. 15, p. 85-86. No cabe duda de que su desgajamiento del subsidio fue un factor muy importante en la fijación definitiva del volumen de las questie.

${ }^{61}$ Véase el análisis de algunos de esos discursos políticos en Suzanne F. CAWSEY, Kingship and Propaganda. Royal eloquence and the Crown of Aragon, c. 1200-1450, Oxford UP, 2002.
} 
paulatina de este nuevo recurso fiscal a todo el realengo, iniciado por las ciudades en $1322-23$ y proseguido por las villas-mercado en 1334 y $1338^{62}$. Por tanto, mediada la década de 1340, comenzaba el big bang -en feliz expresión de Max Turull- que conduciría a la consolidación definitiva del sistema fiscal municipal en Cataluña, estimulado, como venimos viendo, por las exigencias de la Corona. A los recursos fiscales de las tallas proporcionales y de las imposicions, no tardaría en añadirse el tercer y definitivo pilar de las finanzas locales: la adopción por parte de los regidores urbanos de la deuda a largo plazo.

Separada de los subsidios y convertida en un recurso patrimonial más, la questia siguió el mismo o parecido destino que el resto de los componentes del patrimonio regio en aquella difícil época para las finanzas reales: su alienación total o parcial. No voy a entrar en ello puesto que el tema correspondería más bien a las estrategias financieras de la Corona y nos alejaría considerablemente de nuestro objetivo. Pero sí quiero aludir a una cuestión de cierta importancia, que tuvo hondas consecuencias en el futuro de las finanzas urbanas: la conversión de la questia en pensiones de deuda a largo plazo, emitida por algunos municipios a instancias de la Corona. Veámosla aunque sea muy por encima ${ }^{63}$.

Como he apuntado más arriba, en 1342 y 1344, Pedro el Ceremonioso logró importantes donativos para financiar la guerra que concluiría con la definitiva incorporación del reino de Mallorca a la Corona de Aragón. Otra importante porción del dinero necesario para llevar a cabo las campañas de las Baleares y del Rosellón se obtuvo de la masiva alienación de bienes patrimoniales. Pero, junto a castillos, honores, lugares, rentas, censos y otros componentes del patrimonio real, la Corona procedió también a la alienación del tributo regio por antonomasia - la questia -, transformándola en pensiones de violarios y censales. Para proceder a esta operación financiera, cada una de las villas implicadas - enseguida veremos cuáles- fueron requeridas a enviar a Barcelona, en los primeros meses de 1343, síndicos especiales provistos de los poderes pertinentes para proceder a la venta de rentas asignadas sobre la questia. Como he dicho en otras ocasiones, se trataba de un juego a tres bandas: por una parte, el tesorero real, que recibía inmediatamente el precio de las rentas vendidas y podía emplearlo en la

\footnotetext{
${ }^{62}$ Naturalmente, no en todos los lugares se desarrollaba la actividad comercial necesaria para obtener los donativos a través de impuestos indirectos sobre el mercado. Por ejemplo, los jurados de Castellfollit confesaban su imposibilidad de establecer imposicions debido a la escasa importancia de la villa y al hecho de que en ella no se celebraba mercado. Lo mismo cabría decir del pequeño lugar de Tagamanent, que tampoco celebraba mercado, a cuyos dirigentes el rey autorizo a suprimir la imposició y a sustituirla por una talla. Véanse estos y otros ejemplos en $\mathrm{M}$. SÁNCHEZ; S. GASSIOT, "La "Cort General" de Barcelona, cit., p. 236-237.

${ }^{63} \mathrm{He}$ tratado la cuestión con mayor profundidad en M. SÁNCHEZ, La Corona en los orígenes del endeudamiento censal de los municipios catalanes (1343-1344), en D. MENJOT; M. SÁNCHEZ, Fiscalidad de Estado y finanzas municipales, cit., p. 239-273. Lo que sigue es un escueto resumen de este trabajo.
} 
preparación de la guerra, objetivo esencial de la operación; por otra parte, un buen puñado de ciudadanos de Barcelona, que se mostraron dispuestos a prestar al rey determinadas cantidades, recibiendo como intereses las pensiones de los violarios y censales vendidos por las villas; y, por fin, los núcleos de realengo implicados en la operación, que vieron la questia anual que debían abonar al rey convertida en una o varias pensiones pagadas a barceloneses.

Los lugares convocados por el rey para proceder a esta operación, cuidadosamente organizada por el tesorero real, fueron la ciudad de Manresa y las villas de Cervera, Santpedor, Vilafranca, Igualada, Cubelles, Piera, Montblanc, Besalú, Tàrrega, Vilagrassa, Terrassa y Granollers ${ }^{64}$. Como resultado, los regidores de todos esos núcleos urbanos emitieron un total de 42 rentas, en su inmensa mayoría violarios, vendidos a dos vidas y al interés habitual del 14,28\%. En otros casos, no se trató de la venta de rentas más o menos equivalentes a la questia anual sino, lisa y llanamente, de la exención de este tributo a cambio del préstamo al rey de una crecida suma ${ }^{65}$.

Si en 1343 fueron sólo unas cuantas villas las implicadas en la operación, al año siguiente lo fueron todos y cada uno de los enclaves de realengo. En efecto, para financiar una parte del donativo ofrecido por el brazo real en el Parlamento de 1344, el rey ordenó que todas las ciudades y villas de Cataluña — desde Barcelona a Mura — vendiesen rentas por el alcance de los dos primeros plazos del donativo y consignadas sobre las imposicions concedidas por el rey para pagarlo ${ }^{66}$. Las consecuencias de esta primera emisión general de rentas inducida por la Corona fueron muy importantes para las villas.

En primer lugar, las ventas de censales y violarios por parte de la práctica totalidad de las comunidades de realengo, con todo lo que ello implicaba (capacidad jurídica para proceder a la venta, potestad para garantizarla con los bienes de la universidad ante la corte del veguer, recursos fiscales para pagar las pensiones, existencia de algún tipo de administración, por rudimentaria que fuese, para gestionar la deuda, etc.) atestigua, por un lado, el grado de madurez institucional de gran parte de los municipios de Cataluña. Pero, por otro lado, el hecho de que lugares tan minúsculos como Ódena, Mura, Tagamanent o Muntmaneu/La Panadella también se viesen

\footnotetext{
${ }^{64}$ No deberá sorprendernos que esta relación coincida casi exactamente con la de las villasmercado autorizadas por el rey a establecer imposicions en 1333 y 1338. El número y el precio de las rentas vendidas por cada una de estas villas se pueden encontrar en el Cuadro I del trabajo mencionado en la nota anterior.

${ }^{65}$ Así, Cervera prestó al monarca $68.000 \mathrm{~s}$. y, hasta su devolución, estuvo franca de questia; lo mismo cabe decir de Tàrrega/Vilagrassa por un préstamo de $25.000 \mathrm{~s}$. y de Terrassa por $48.000 \mathrm{~s}$. Apenas parece necesario decir que esas villas debieron vender censales y violarios para poder reunir tan importantes cantidades.

${ }^{66}$ Véase el desarrollo de esta compleja operación en M. SÁNCHEZ, La Corona en los orígenes del endeudamiento, cit., p. 247-254.
} 
obligados a vender violarios debió obligar a esas pequeñas comunidades a dotarse de un mínimo aparato fiscal y administrativo para pagar y gestionar la deuda y, más allá, debió contribuir también a fortalecer la propia vertebración de la universidad.

Desde el punto de vista fiscal, las operaciones financieras de 1343 y 1344 no supondrían ningún cambio para las villas que, en principio, actuaban como meras intermediarias. En efecto, los intereses de las rentas vendidas en 1343 se pagarían con un recurso del patrimonio real (la questia) y los de las emitidas en 1344 se abonarían con las cantidades que, en virtud del donativo, las universidades debían pagar al monarca. Por tanto, podemos observar de nuevo la utilización de los municipios como instrumento o instancia intermedia no sólo de la fiscalidad real (cosa que ya sabíamos), sino también de las estrategias financieras de la Corona. En definitiva, la talla que los municipios establecían cada año para pagar la questia real serviría ahora para reunir el dinero de las pensiones de las rentas vendidas, más o menos equivalentes a aquel tributo. Sin embargo, como he dicho en otras ocasiones, habría que medir la distancia que iba entre el pago de una questia al monarca, susceptible de ser negociada dentro de ciertos límites, y el pago de una pensión de censal a un ciudadano de Barcelona en unas fechas muy precisas del año. De hecho, tenemos noticias (por desgracia, poco explícitas) de ciertas resistencias a aceptar la operación propuesta por la Corona ${ }^{67}$.

Sea como fuere, el hecho cierto es que la utilización de las universidades para llevar a cabo las dos operaciones financieras de 1343 y 1344 nos muestra el papel protagonista desempeñado por la Corona no sólo en la génesis de la fiscalidad municipal, sino también en la adopción, por primera vez y de manera generalizada, de la nueva forma de crédito representada por los censales y violarios. Con un poco de retórica, podríamos decir que la Corona hizo pedagogía al respecto y, persuadiéndoles a vender rentas, divulgó las ventajas del nuevo producto financiero hasta los más alejados lugares del Principado. Y es que, si bien es probable (y en algunos casos así nos consta) que en las ciudades y en las grandes villas -Barcelona, Lérida, Cervera, Gerona - la emisión de rentas fuese una práctica ya conocida y utilizada esporádicamente, no cabe ninguna duda de que, en la mayoría de los lugares de realengo, fueron las iniciativas de la Corona las que condujeron a emplear este procedimiento crediticio por primera vez.

\footnotetext{
${ }^{67}$ Por ejemplo, Vilafranca, Cervera, Montblanc y Manresa se mostraron reticentes a enviar los síndicos que habrían de hacer las ventas: los oficiales ordinarios recibieron la orden de sellar los molinos y hornos de aquellas villas que demorasen el envío de procuradores. En otros casos, como los de Besalú o Santpedor, se tratọ́ de las resistencias de algunos vecinos a firmar las ventas o a garantizar con sus bienes la operación.
} 


\section{El destino de las questie entre 1348 y 1359}

La venta, por parte de las villas, de censales y violarios asignados sobre la questia fue altamente rentable para la Corona: gracias al mencionado juego a tres bandas, se obtuvo en 1343, y en apenas cuatro meses, la suma de 18.1251 . a un interés medio que apenas supera el $12 \%$. El éxito de la operación fue la causa de su nueva utilización en 1347 para cubrir entonces los gastos de la expedición que sofocaría la revuelta de los Doria en Cerdeña. En este caso, las nuevas ventas de rentas sobre la questia afectaron otra vez a Manresa, Igualada, Cubelles y Santpedor, pero también a Caldes, Cambrils, Sarral y Els Prats; y, como resultado de la operación, la Corona obtuvo, también en muy breve plazo, la cantidad de $6.6801{ }^{68}$.

Ahora bien, como reverso de la medalla, las operaciones de 1343 y 1347 asestaron un duro golpe a las ya maltrechas questie, en tanto que ingreso regular de la Corona en Cataluña. Tampoco insistiré en una cuestión que pertenece más bien al ámbito de las finanzas regias. Baste decir que, separadas ya de los subsidios, fijado su volumen desde principios de la década de 1340 y erosionado su producto por generosas remisiones (y, sobre todo, por su conversión en pensiones de las rentas vendidas en 1343 y 1347), las questie representaban ya muy poco en las finanzas de la monarquía.

En el período final que ahora consideramos, la questia era exigida rutinariamente a principios de cada año - para ser percibida en los plazos de mayo y septiembre - a la ciudad de Manresa y a las villas que aún estaban obligadas a pagarla, no más de 13 o 15, frente a los casi 30 lugares que abonaban este tributo en la década de 1330. Como he dicho antes, sin necesidad ya de esgrimir una causa finalis que justificase su petición, la cancillería se limitaba a exigir el tributo con un escueto mandamus et dicimus vobis expresse quatenus detis nobis pro questia anni presentis...tal cantidad ${ }^{69}$. Por lo que respecta a su rendimiento, de aquellas 13 o 15 villas en las que se percibían questie entre 1348 y 1359, la Corona obtenía unos 8.300 s., frente a los cerca de 70.000 s. que recibía de 30 lugares una veintena de años antes.

\footnotetext{
${ }^{68}$ Véase M. SÁnchez, Después de Aidu de Turdu (1347): los sucesos de Cerdeña y sus repercusiones en el patrimonio real, "XIV Congresso di Storia della Corona d'Aragona [SassariAlghero, 1990], Vol. II (Comunicazioni), t.II, Sassari, 1995, p. 789-809.

${ }^{69}$ Pueden reconstruirse las questie del período 1341-1359 a través de tres fuentes documentales: 1) los registros de cancillería n ${ }^{\circ} 1502,630,1472$ y 1473; 2) el largo albarán testimonial extendido a Ramon de Margens, ciudadano de Barcelona y recaudador vitălicio de las questie de Cataluña por muerte de Pere Ponç - había desempeñado la misma función entre noviembre de 1340 y su muerte ( $;$ a causa de la Peste?) en junio de 1348 - entre agosto de 1348 y el mismo mes de 1359; el albaran recoge las questie recaudadas entre 1348 y 1355 (RP, MR, $\mathrm{n}^{\circ} 642$, fols $242 \mathrm{v}$-253v.); y 3) un bien conservado libro de cuentas del mismo Ramon de Margens (C, Varia, $\mathrm{n}^{\circ} 37$ ), donde se detallan las questie pedidas por él entre 1356 y el primero de agosto de 1359 . En esta última fecha. Pedro el Ceremonioso concedía las questie de Cataluña a la provisión de la casa del infante Juan, duque de Girona; Bernat Margarit, expensor del infante, sería el encargado de percibirlas cada año, no sin antes pagar las pensiones asignadas sobre dichos tributos (reg. 1538, fol. 84r.).
} 
Veamos tres ejemplos un poco más concretos: mientras las questie de Manresa, Vilafranca, Piera, Igualada, Santpedor, Besalú y Cubelles habrían supuesto, entre 1348 y 1359, unos ingresos medios de $26.500 \mathrm{~s}$. anuales, el recaudador sólo cobró una media de 4.500 s., esto es, casi una sexta parte menos, debido casi exclusivamente a la conversión de la mayor parte de este tributo en pensiones de las rentas vendidas en 1343 y en 1347. Por otra parte, de los $120.000 \mathrm{sb}$. que la Corona debía haber recibido de Vilafranca del Penedès entre 1348 y 1359 , apenas se percibieron $14.700 \mathrm{sb}^{.70}$. Por último, digamos que la importante questia/subsidio de Cervera (evaluable en 18.000 s. anuales entre 1337 y 1339) escapó a la Corona durante treinta años: exenta la villa, como hemos visto, mediante el pago de 68.000 s., este tributo no sería reestablecido hasta 1373, cuando el infante Joan redimió la pensión del censal vendido por la villa en 1343 para pagar dicha exención.

De todas formas, el hecho de que las questie fuesen un ingreso muy poco relevante para las finanzas de la Corona a mediados del s. XIV, no quiere decir que dejaran de gravar pesadamente sobre las villas que aún debían pagarla. Pensemos que, durante la década de 1350, las villas estuvieron sometidas al pago de numerosos subsidios para sufragar las campañas mediterráneas de Pedro el Ceremonioso, a los que pronto vendrían a añadirse los impuestos inherentes a la nueva fiscalidad de Estado, establecida entre 1362 y 1365 . Así, a las cargas de los fogatges, las generalitats, las imposicions extraordinarias y otras exigencias de la Corona, la vieja questia continuaría haciéndose sentir, allá donde aún se exigiese, y contribuiría a agravar aún más los frágiles equilibrios financieros de muchas villas en el último tercio del siglo $\mathrm{XIV}^{71}$. Todo ello, sin embargo, debería estudiarse a partir de la documentación local.

Así pues, mediada la década de 1340 y de forma creciente según avanzamos en el tiempo, se habían producido unas transformaciones muy significativas en las relaciones fiscales que el monarca mantenía con las ciudades y villas de realengo. Por una parte, las comunidades catalanas empezaron a pagar donativos cada vez más cuantiosos (sobre todo, a lo largo de la década de 1350) negociados conjuntamente en Cortes y Parlamentos; en parte gracias a ellos, el Ceremonioso pudo llevar a cabo una tenaz política mediterránea durante los primeros veinte años de su reinado. Por otro lado,

\footnotetext{
${ }^{70} \mathrm{El}$ final de este proceso de reducción a la nada de la questia de Vilafranca lo muestra muy gráficamente un capbreu de 1425: los 10.000 sb. de aquel tributo ordinario habían sido "venuts o empenyorats" a capellanías, aniversarios, iglesias o personas particulares, por lo que, en el mencionado año, el batlle general "no'n fa rebuda alguna" (cf. M. SÁNCHEZ, La estructura del dominio real en Vilafranca del Penedès y en los castillos de Cubelles/Vilanova y de La Geltrú en el primer tercio del S. XV, "Miscel-lània de Textos Medievals", 6, Barcelona, 1992, p. 215-216).

${ }^{71}$ Véanse, como simple ejemplo, las angustiosas negociaciones de los pequeños lugares de Montmaneu y La Panadella para conseguir Ta fijación de su questia; cf. M. SANCHEZ, Entre el realengo y el señorí: un conflicto jurisdiccional entre Santes Creus y la universitat de Montmaneu/La Panadella (1382), en Miscel lània en homenatge al P. Agustí Altisent, Tarragona, 1991, p. 347-349.
} 
aquellas villas que todavía estaban obligadas a pagar la questia siguieron abonándola, aunque en muchos casos (quizás los más significativos y consistentes) el destinatario del tributo no era el monarca sino los compradores de las rentas que las villas vendieron por iniciativa regia.

Ya sea por esta última razón - la venta de censales y violarios en 1343 y 1347 sobre la questia - , ya sea por la necesidad de reunir en breve plazo las grandes cantidades ofrecidas por el brazo real en las asambleas de los años 1350, la emisión masiva de rentas durante este período es, sin duda, el dato mayor de la vida financiera de los municipios catalanes. Como es bien sabido, la adopción generalizada de la deuda a largo plazo, cuyos intereses serían satisfechos con los impuestos indirectos (imposicions) otorgados por el rey, contribuyó decisivamente a consolidar el sistema fiscal municipal, al tiempo que confirió crecientes cotas de autonomía financiera a las universidades catalanas. No olvidemos que los donativos negociados en las asambleas conservaban su carácter voluntario, es decir, se concedían non ex debito; ello quiere decir que sobre los regidores municipales recaían todas las competencias referentes a la gestión de los recursos fiscales y de los instrumentos financieros puestos a punto para pagar dichos subsidios.

Por tanto, al filo de 1359, esto es, en vísperas del establecimiento de la nueva fiscalidad de Estado en Cataluña, poco o casi nada quedaba ya de aquellas questie/subsidios de una veintena de años antes, que el rey había utilizado como un importante recurso de financiación y que las villas habían negociado trabajosamente cada año a cambio de arrancar a la Corona algunas concesiones más o menos relevantes.

\section{CONSIDERACIONES FINALES}

En las páginas anteriores he mostrado cómo la necesidad de pagar casi anualmente una questia/subsidio al monarca debió contribuir al paulatino desarrollo de la organización fiscal y financiera de todas las comunidades realengas del Principado, incluso de los más pequeños núcleos rurales. Pero, más allá de aquel ámbito, he mostrado también que la particular dinámica de las questie/subsidios - una questia obligatoria y un subsidio pactado- otorgó a los dirigentes urbanos un destacado protagonismo en la negociación con los oficiales de la corte. Y aunque (salvo excepciones muy concretas) no dispongamos de la documentación más adecuada para conocer los términos de dicha negociación, sabemos con certeza por los propios registros de cancillería aquí utilizados que, año tras año, las villas destacaban sus procuradores, bien para concertar el alcance del subsidio que el monarca pedía más allá de la questia, bien para lograr alguna remisión de este tributo. No cabe duda de que estas capacidades para negociar, con todo lo que ello implica, debieron contribuir también a reforzar los lazos comunitarios y el entramado institucio- 
nal de las universidades ${ }^{72}$. En resumidas cuentas, aunque parciales y limitados, los datos aportados por los registros de la serie Subsidiorum permiten valorar el grado de desarrollo fiscal e institucional de muchos municipios catalanes ya en el primer tercio del s. XIV. Por tanto, sería deseable que los investigadores de la historia de las villas del Principado no dudasen en utilizar, entre otro material, los mencionados registros con el fin de suplir o, en su caso, complementar la documentación generada por el propio municipio.

Dije al principio que el material utilizado, aparte de su interés primordial para la fiscalidad, también brindaba otro tipo de datos de cierta relevancia para la propia historia de las villas. Destaquemos con brevedad algunos de ellos.

Puesto que la alienación de un lugar determinado implicaba casi siempre la enajenación de la questia, la consulta de los registros de la serie Subsidiorum proporciona una rápida instantánea - a completar después con otra documentación más idónea- de aquellos lugares que pasaron del patrimonio real a manos privadas en un momento dado. He aquí algunos ejemplos entre muchos. En la petición de la questia/subsidio de $1311^{13}$, las villas de Piera e Igualada no pagaron el tributo porque habían sido enajenadas de por vida a Ramon Folc de Cardona; ésos fueron también los casos del castillo de Moià, entregado a carta de gracia a Sibil la de Saga por un préstamo concedido al rey; de Caldes de Malavella, cedida a Guillem Esquerrer también a carta de gracia; de Molins de Rei, traspasada a los condes de Pallars por la permuta de Berga; de Montcortès, entregada a Berenguer de Jorba, a carta de gracia, por un préstamo al monarca, etc. En 1314, sabemos que el vizcondado de Bas había sido devuelto a Malgaulí, conde de Empúries, por lo que se anotaba en el registro correspondiente que en adelante no se exigiesen questie ${ }^{74}$. Por otra parte, en octubre de 1314, Jaime II empeñó los lugares de Camarasa, Cubells, Montgai, Sant Linya, Llorenç, Almenar y de las Montañas de Prades a los albaceas del conde de Urgell por la compra de este condado y del vizcondado de Àger ${ }^{75}$. Parece que estos lugares no volvieron a la Corona pues, junto a muchos otros, formaron parte de las famosas donaciones - grávidas de consecuencias- hechas por Alfonso el Benigno a su hijo el infante Fernando, marqués de Tortosa ${ }^{76}$. En

\footnotetext{
${ }^{72}$ Además, si la negociación con los oficiales de la corte concluía con éxito, el municipio lograba concesiones y privilegios a cambio de pagar un subsidio apropiado. Estoy convencido de que una observación sistemâtica de las fechas de obtención de determinados privilegios por muchas yillas (a través, por ejemplo, de los libros de privilegios publicados) mostraría significativas coincidencias con la cadencia de las peticiones de questie/subsidios.

${ }^{73}$ Reg. 326, fols. 70r.-75v.

${ }^{74}$ Questia/subsidio de 1314 (reg. 327, fols. 155r.-162v.).

${ }^{75} \mathrm{Se}$ informaba a los albaceas de las cantidades que se debían de exigir como questia a dichos lugares (questia/subsidio de 1316, reg. 327, fols. 198r.-204v.).

${ }^{76}$ Cf. M. SÁNCHEZ, "Questie”, cit., p. 18-19.
} 
los años del citado monarca, sabemos que la questia de Gàver estaba asignada a Guerau d'Oluja, que la recibía desde 1309 por la guardia del castillo; y que, por ejemplo, las villas de Cardedeu y Vilamajor fueron donadas en franco alodio a Berenguer de Sentmenat en octubre de 1328. Con estos pocos ejemplos, que sería ocioso multiplicar, sólo he querido mostrar que el simple repaso de estos registros - no lo olvidemos, continuos desde 1309- nos refleja con cierta exactitud la geografía cambiante del patrimonio real durante la primera mitad del s. XIV, al anotar cuidadosamente los lugares incorporados a la Corona (los menos) y, sobre todo, los enajenados del señorío regio.

En ocasiones, esta documentación puede proporcionar datos insospechados como, por ejemplo, aquellos que nos permiten datar con cierta exactitud la extinción de las comunidades musulmanas de Barcelona y de Gerona en el segundo decenio del s. XIV. Al parecer, los musulmanes alforri de ambas ciudades pagaban como questia una cantidad global que era repartida entre los individuos de cada comunidad. Pues bien, con ocasión de la questia/subsidio de 1316, se ordenó que los musulmanes de Barcelona, probablemente muy pocos, dejasen de pagar questia específica y que contribuyesen con el resto de los barceloneses en las tallas que establecía el municipio. Y, al año siguiente, también se ordenó que no se exigiese questia a los musulmanes alforri de Gerona, porque sólo vivían en la ciudad una o dos familias y eran pobres ${ }^{77}$.

También me parecen dignas de destacar las abundantes referencias que aparecen en estos registros acerca de las franquicias de questia (totales o parciales, temporales o perpetuas) de que gozaban muchas villas. Ya me he referido más arriba a la franquicia de Figueres, exenta de este tributo desde 1267 y 1295; lo mismo cabría decir, por ejemplo, de los habitantes de Palamós, liberi et franchi de omni questia et tolta desde 1279; y de los moradores de Vic, franchs de quèstia ab privilegi del senyor rey ${ }^{78}$. También me he referido más arriba a la franquicia parcial de que gozaban Besalú (por 10 años) y Torroella de Montgrí (por 20 años) desde 1305 y 1302 respectivamente, siempre que empleasen $2.000 \mathrm{~s}$. anuales en la reparación de los puentes de ambas villas ${ }^{79}$.

${ }^{77}$ Questie/subsidios de 1316 y 1317 (reg. 327, fols. 198r.-204v. y 228r.-234r.).

${ }^{78}$ Véase M. SÁNCHEZ, “Questie”, cit., p. 16-17.

${ }^{79}$ Por cierto que la corte mantenía un estrecho control sobre dichas obras públicas para proceder en consecuencia y mantener (o no) las franquicias otorgadas. Así, los trabajos del puente de Besalú se hacían bajo el control del batlle real de la villa y el consejo de dos prohoms; y, en la questia/subsidio de 1311, se esperó a aplicar la exención hasta que se hubiese comprobado que las obras avanzaban satisfactoriamente (reg. 326, fol. 75r.). Por el contrario, en 1316, una vẹz comprobado el hecho de que no se efectuaban trabajos en el puente, fue suprimida la franquicia de Torroella y se le exigio una questia/subsidio de $6.000 \mathrm{~s}$ s; al mismo tiempo, se ordenaba al batlle de Gerona y al procurador real de Torroella y Pals que auditasen las cuentas de los responsables de las obras, se asesorasen con expertos e inspeccionasen personalmente los trabajos para ver si procedía respetar la franquicia (reg. 327 , fol. 198v.). 
A veces, la documentación utilizada deja escapar algunas noticias incidentales acerca de los motivos por los que el rey reducía o perdonaba del todo la questia debida por algunos lugares. En ocasiones, el tributo era rebajado o suprimido como indemnización por el servicio de host que había realizado la villa en cuestión, dato éste de cierto valor para documentar algunas salidas de las host vecinales en una época poco abundante en fuentes municipales. Por ejemplo, en 1311, la ciudad de Manresa, las villas de Santpedor, Caldes de Montbui, Terrassa y los habitantes del término castral de Mura obtuvieron una consistente rebaja de su questia por el servicio de host que prestaron en el conflicto que oponía a Jaime II con Ponç Hug IV de Empúries $^{80}$.

Otras veces, la reducción o supresión del tributo eran consecuencia de las inclemencias metereológicas que habían reducido la capacidad contributiva de los habitantes del lugar. A pesar de la precaución con que deben tomarse estos datos, creo que pueden ser interesantes para suplir provisionalmente la ausencia de noticias más fiables. Por ejemplo, en agosto de 1314, los habitantes del término del castillo de Mura vieron suprimida su questia porque el granizo había destrozado las cosechas. Cuatro años más tarde, a principios de septiembre de 1318, se redujo el tributo de Caldes de Montbui en $2.000 \mathrm{~s}$. porque el granizo había arruinado los viñedos y los campos de cereal; no obstante, fue enviado un porter real con el fin de certificar dichos daños. Y en 1328, los nuncios de Sarral, Cabra y Forès obtuvieron del rey una remisión total de la questia... propter grandinem et ariditatem ac etiam sterilitatem fructuum que, desde hacía cinco años, afectaban a la comarca ${ }^{81}$. No menos relevantes son las referencias a zonas despobladas tras la Peste Negra, por desgracia, no tan abundantes como habríamos deseado. Así, en 1348, no se percibió la questia de Timor porque el dit loch era tot despoblat; en 1349, se redujo en $250 \mathrm{~s}$. el tributo de Besalú durante tres años a causa de la mortandad; y en 1351, se rebajó en 278 s. la questia de Gurb a cuenta de los mansos deshabitados ${ }^{82}$.

Estos pocos ejemplos, que he seleccionado entre decenas, sólo pretenden mostrar el tipo de informaciones que puede obtenerse de estos registros, más allá de las escuetas cifras exigidas como questia.

No querría concluir estas páginas sin proporcionar al lector algunas pistas sobre la jerarquía de las villas catalanas de realengo en función de su contribución a la questia durante el período aquí considerado. Como puede comprenderse, no es una cuestión fácil si queremos hilar muy fino: como ya

\footnotetext{
${ }^{80}$ Questia/subsidio de 1311 (reg. 326, fols. 70r.-75v.).

${ }^{81}$ Véanse respectivamente la questia/subsidio de 1314 (reg. 327, fols. 155r.-162v.) y de 1318 (reg. 328, fols. 36r.-43r.); y reg. 543, fol. 39r.

${ }^{82}$ Véanse respectivamente, RP, MR, $\mathrm{n}^{0}$ 642, fol. 244r.; C, reg. 630, fol. 125r.; y RP, MR, $\mathrm{n}^{0} 642$, fol. $247 \mathrm{r}$.
} 
sabemos de sobra, algunas villas y ciudades no figuran en nuestras listas (o lo hacen muy esporádicamente) por estar exentas de questia, como Figueres o Vic, por ejemplo. Otras veces, el tributo estaba fijado por privilegio real, en cuyo caso la cantidad solicitada no tiene porqué guardar relación con el tamaño e importancia del núcleo urbano en cuestión. Por fin, en otras ocasiones, las villas no se visualizan en los registros a partir de determinado momento porque habían sido alienadas del patrimonio real. Quiero decir con todo ello que, sin una investigación pormenorizada y villa por villa, es difícil retener unas cifras que, en todos los casos, sirvan para jerarquizar de manera relativamente exacta los núcleos de realengo del Principado a lo largo de medio siglo.

De todas formas, si queremos aproximarnos de manera un poco más superficial y rápida a esta cuestión, me parece que las cifras más coherentes y relativamente fiables son las del donativo votado en las Cortes de Montblanc de $1333^{83}$. Según la relación ordenada que damos en Apéndice (donde faltan, entre otras, la villa de Figueres y la ciudad de Vic), figuran a la cabeza Cervera (con gran diferencia, el lugar que más contribuyó de todo el realengo en las questie/subsidios del primer tercio del s. XIV), Manresa y las ciudades medianas de Tàrrega/Vilagrassa, Montblanc y Vilafranca del Penedès. A continuación, fluctuando entre los $1.500 \mathrm{~s}$. y los $5.000 \mathrm{~s}$., figuran un conjunto de pequeñas ciudades, entre otras, Camprodon, Piera, Terrassa, Caldes, Berga, Sarral, Besalú, Torroella, Cubelles, Igualada, Santpedor y L'Arbóç. Como hemos visto más arriba, todos estos enclaves, probables centros de un activo comercio supralocal, recibieron en 1334 y 1338 la autorización regia para percibir los subsidios a través de impuestos indirectos. Esta particularidad quizás estuvo en la base de que el monarca eligiese a casi todos ellos para vender violarios y censales sobre la questia en 1343 y 1347. Por fin, seguían un grupo de pequeños lugares (tasados con menos de $1.000 \mathrm{~s}$.), que van desde Font-rubí o Pujalt hasta Gimenells, Timor o Gàver, pasando por Montmaneu/La Panadella, Gurb o Argençola.

Hemos llegado al final de nuestro recorrido por las relaciones fiscales que, en torno a las questie/subsidios, se establecieron entre la Corona y las villas de realengo durante la primera mitad del s. XIV. Las páginas anteriores habrán valido la pena si consiguen atraer la atención de los investigadores del hecho urbano catalán hacia los registros de naturaleza fiscal y financiera conservados en el Archivo de la Corona de Aragón, que todavía pueden

\footnotetext{
${ }^{83}$ Recordemos que en esta asamblea, los síndicos de todas y cada una de las villas reales ofrecieron una cantidad global al rey, una parte de la cual (la mitad o un tercio, según los lugares) sería recibida por el rey como questia y el resto por los clavaris que gestionaron el subsidio. Puesto que han sido localizadas las ápocas extendidas por dichos clavaris, donde consta la cantidad que cada lugar pagó como subsidio extraordinario, sabemos con bastante precisión lo que las villas que entonces pertenecían al realengo abonaron como questia; véanse M. SÁNCCHEZ; $\mathrm{P}$. ORTí, La Corona en la génesis del sistema fiscal municipal, cit., Cuadro I; y M. SÁNCHEZ, "Questie", cit., p. 28-30 y Cuadro V.
} 
deparar muchas sorpresas y proporcionar noticias de calidad sobre el hecho urbano en la Cataluña bajomedieval.

Fecha de recepción del artículo: septiembre 2007.

Fecha de aceptación y versión final enero 2008. 


\section{APÉNDICE}

La “questia” de las villas de realengo en $1333^{84} \mathrm{y}$

\begin{tabular}{|l|c|}
\hline Cervera* & $18.000 \mathrm{~s}$. \\
\hline Vilafranca del Penedès* & $10.000 \mathrm{~s}$. \\
\hline Manresa* & $10.000 \mathrm{~s}$. \\
\hline Tàrrega/Vilagrassa* & $10.000 \mathrm{~s}$. \\
\hline Montblanc* $^{*}$ & $10.000 \mathrm{~s}$. \\
\hline $\begin{array}{l}\text { Prats del Rei, La Manresana, } \\
\text { pons }{ }^{* 85}\end{array}$ & $4.000 \mathrm{~s}$. \\
\hline Camprodia Pilosa, Veciana, Co- & $3.333 \mathrm{~s}$. \\
\hline Piera* & $3.333 \mathrm{~s}$. \\
\hline Terrassa* & $3.200 \mathrm{~s}$. \\
\hline Caldes de Montbui* & $3.000 \mathrm{~s}$. \\
\hline Berga & $3.000 \mathrm{~s}$. \\
\hline Forès & $2.250 \mathrm{~s}$. \\
\hline Sarral* & $2.250 \mathrm{~s}$. \\
\hline Besalú* & $2.000 \mathrm{~s}$. \\
\hline
\end{tabular}

${ }^{84}$ Véase M. SÁNCHEZ; P. ORTÍ, La Corona en la génesịs del sistema fiscal municipal, cit., Cuadro I, p. 271-272. Los lugares que van en letra negrilla fueron autorizados a establecer imposicions en 1334 y 1338; y los que van seguidos de asterisco vendieron censales y violarios sobre la questia en 1343 y 1347.

${ }^{85}$ Sobre este batlliu véase F. SABATÉ, El territori de la Catalunya medieval, Barcelona, 1997, p. 200-202 y figura 39. 


\begin{tabular}{|l|l|}
\hline Torroella de Montgrí & $2.000 \mathrm{~s}$. \\
\hline Cubelles* & $2.000 \mathrm{s.}$ \\
\hline Igualada* $^{*}$ & $2.000 \mathrm{s.}$ \\
\hline Santpedor* & $2.000 \mathrm{~s}$. \\
\hline L'Arbóç & $1.666 \mathrm{~s}$. \\
\hline Cabra & $1.500 \mathrm{s.}$ \\
\hline Pallerols/Sant Antolí & $1.400 \mathrm{~s}$. \\
\hline Cambrils* & $1.250 \mathrm{~s}$. \\
\hline Font-rubí & $800 \mathrm{~s}$. \\
\hline Pujalt & $800 \mathrm{~s}$. \\
\hline Berguedà & $800 \mathrm{~s}$. \\
\hline Pals & $700 \mathrm{~s}$. \\
\hline Almacelles & $666 \mathrm{~s}$. \\
\hline Granollers* & $600 \mathrm{~s}$. \\
\hline Montmaneu/La Panadella & $600 \mathrm{~s}$. \\
\hline Gurb & $500 \mathrm{~s}$. \\
\hline Argençola & $500 \mathrm{~s}$. \\
\hline Sedó/Riber & $500 \mathrm{~s}$. \\
\hline Tagamanent & $400 \mathrm{~s}$. \\
\hline Mura & $400 \mathrm{~s}$. \\
\hline Giminells & $333 \mathrm{~s}$. \\
\hline Timor & $300 \mathrm{~s}$. \\
\hline Gàver & $100 \mathrm{~s}$. \\
\hline
\end{tabular}

